\title{
Specific deletion of protein phosphatase 6 catalytic subunit in Sertoli cells leads to disruption of spermatogenesis
}

\author{
Wen-Long Lei ${ }^{1,2,3}$, Yuan-Yuan $\mathrm{Li}^{4}$, Tie-Gang Meng $\mathbb{D}^{4,5}$, Yan Ning ${ }^{4}$, Si-Min Sun ${ }^{4}$, Chun-Hui Zhang ${ }^{1,3}$, Yaoting Gui ${ }^{3}$, \\ Zhen-Bo Wang (iD ${ }^{4{ }^{凶}}$, Wei-Ping Qian (iD ${ }^{1,3 \bowtie}$ and Qing-Yuan Sun (iD ${ }^{5 凶}$
}

(c) The Author(s) 2021

Protein phosphatase 6 (PP6) is a member of the PP2A-like subfamily, which plays significant roles in numerous fundamental biological activities. We found that PPP6C plays important roles in male germ cells recently. Spermatogenesis is supported by the Sertoli cells in the seminiferous epithelium. In this study, we crossed $P p p 6 c^{F / F}$ mice with $A M H$-Cre mice to gain mutant mice with specific depletion of the Ppp6c gene in the Sertoli cells. We discovered that the PPP6C cKO male mice were absolutely infertile and germ cells were largely lost during spermatogenesis. By combing phosphoproteome with bioinformatics analysis, we showed that the phosphorylation status of $\beta$-catenin at S552 (a marker of adherens junctions) was significantly upregulated in mutant mice. Abnormal $\beta$-catenin accumulation resulted in impaired testicular junction integrity, thus led to abnormal structure and functions of BTB. Taken together, our study reveals a novel function for PPP6C in male germ cell survival and differentiation by regulating the cell-cell communication through dephosphorylating $\beta$-catenin at S552.

Cell Death and Disease (2021)12:883; https://doi.org/10.1038/s41419-021-04172-y

\section{INTRODUCTION}

Spermatogenesis is an intricate developmental process by which spermatogonial stem cells (SSCs) renovate and differentiate to produce mature spermatozoa, consisting of three phases: spermatogonial mitosis, spermatocytic meiosis, and spermiogenesis [1]. Any errors in this process can result in serious outcomes including infertility $[2,3]$. In addition to germ cells, there are some other somatic cells in the seminiferous epithelium, such as Sertoli cells, which have significant functions in spermatogenesis. Germ cells and Sertoli cells form a series of connection structures to support the transfer of signaling elements, attachment, and germ cell differentiation [4]. Destruction of Sertoli cell can disrupt germ cell differentiation and spermatogenesis.

In the mammalian testis, blood-testis barrier (BTB) is found between the adjacent Sertoli cells within the seminiferous tubules, which divided the seminiferous epithelium into the basal and the apical compartments. Germ cell meiosis completion, spermiogenesis occur in the apical compartment, whereas SSCs division and differentiation to preleptotene spermatocytes take place in the basal compartment $[5,6]$. Therefore, the BTB forms an immunological microenvironment for meiotic and postmeiotic cells [7]. Unlike other blood-tissue barriers forming by a tight junction (TJ) [8], the BTB is constituted by several types of cell-cell junctions, such as $T J$, adhesion junction (AJ), gap junction (GJ) and desmosome-like junction, and numerous junctional proteins are involved in the formation of BTB [7].

Protein phosphorylation and dephosphorylation always occur in spermatogenesis [9]. The dynamic changes of protein phosphorylation levels are controlled by a conserved series of protein kinases and protein phosphatases. Among these numerous phosphatases, PP2A, PP4, and PP6 constitute the type $2 \mathrm{~A}$ subfamily within the serine/threonine protein phosphatase family [10]. Type $2 \mathrm{~A}$ subfamily have important functions in lots of fundamental cellular processes [11, 12]. Like other type $2 \mathrm{~A}$ phosphatases, PP6 also works as a holoenzyme and is evolutionally conserved among eukaryotes, indicating its importance. Previous studies found that PP6 plays pivotal roles in cell/organ size regulation, inflammatory signaling, pre-mRNA splicing [13-15], the G1-S transition, S phase arrest [16-18], and mitotic spindle formation [19]. Moreover, a study showed that PP6 may have an effect on the dephosphorylation of $\mathrm{y}-\mathrm{H} 2 \mathrm{AX}$ [20]. Our lab found that conditional knockout (CKO) of PPP6C in male germ cells leads to complete infertility and germ cells are arrested at the pachytene stage [21]. PPP6C is also occurs in Sertoli cells, however, the functions of PPP6C in Sertoli cells is still absolutely unknown.

In this study, we crossed Ppp6c ${ }^{F / F}$ mice with $A M H$-Cre mice to gain mutant mice with specific depletion of the Ppp6c gene in Sertoli cells. We discovered that the PPP6C-deficient cKO mice were absolutely infertile and germ cells were evidently lost during

\footnotetext{
${ }^{1}$ Department of Reproductive Medicine, Peking University Shenzhen Hospital, Shenzhen 518036, China. ${ }^{2}$ CAS Key Laboratory of Quantitative Engineering Biology, Shenzhen Institute of Synthetic Biology, Shenzhen Institutes of Advanced Technology, Chinese Academy of Sciences, Shenzhen 518055, China. ${ }^{3}$ Guangdong and Shenzhen Key Laboratory of Male Reproductive Medicine and Genetics, Institute of Urology, Peking University Shenzhen Hospital, Shenzhen PKU-HKUST Medical Center, Shenzhen 518036, China. ${ }^{4}$ State Key Laboratory of Stem Cell and Reproductive Biology, Institute of Zoology, Chinese Academy of Sciences, Beijing 100101, China. ${ }^{5}$ Fertility Preservation Lab, Guangdong-Hong Kong Metabolism \& Reproduction Joint Laboratory, Reproductive Medicine Center, Guangdong Second Provincial General Hospital, Guangzhou 510317, China. 凶email: wangzb@ioz.ac.cn; qianweipingsz@126.com; sunqy@gd2h.org.cn Edited by Dr. Yufang Shi
}

Received: 23 April 2021 Revised: 25 August 2021 Accepted: 15 September 2021

Published online: 27 September 2021 
A

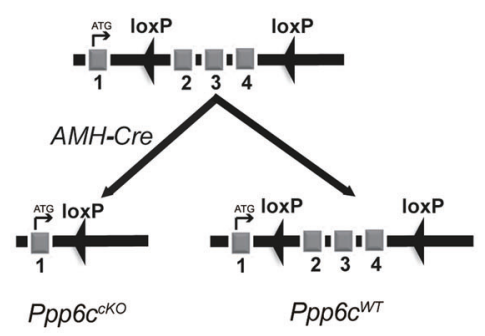

C

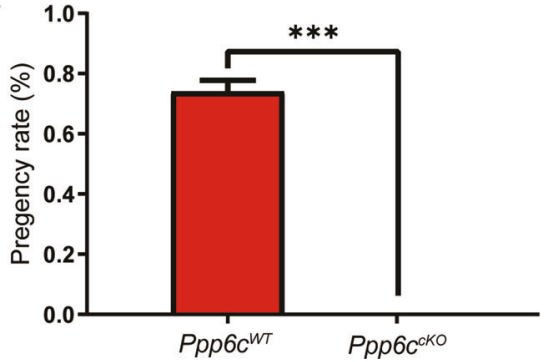

B
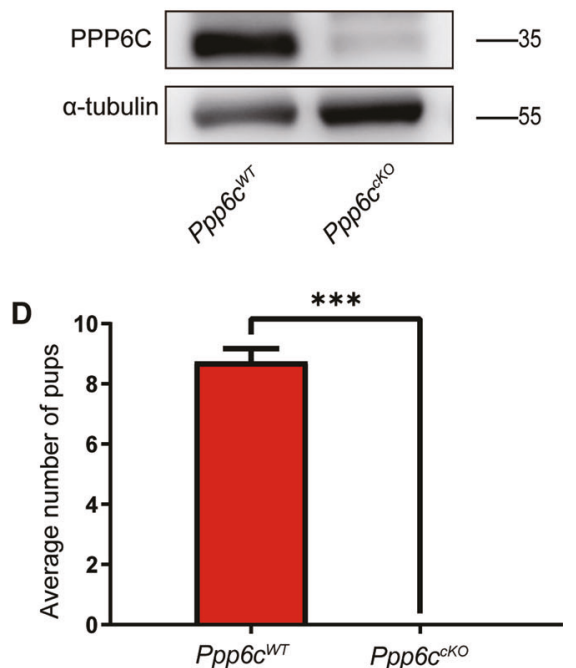

Fig. 1 PPP6C is essential for male fertility. A Schematic diagram of deletion of Ppp6c exons and creation of $P p p 6 c \triangle$ allele by $A M H-C r e-$ mediated recombination in Sertoli cells. B Western blotting analysis of PPP6C protein in Ppp6c ${ }^{W T}$ and Ppp6c $c^{c K O}$ Sertoli cells of 8-week-old mice. $\alpha$-tubulin was detected as an internal control. C Pregnancy rates (\%) of plugged wild-type females after mating with Ppp6c $c^{c K O}$ or Ppp6c ${ }^{W T}$ 8-week-old males. D Average litter size of plugged wild-type females after mating with Ppp6c ${ }^{c K O}$ or Ppp6c ${ }^{W T} 8$-week-old males. For this part, at least 3 mice (8-week-old) of each genotype were used for analysis. Data are presented as the mean $\pm \operatorname{SEM} . P<0.05\left(^{*}\right), 0.01\left(^{* *}\right), 0$ or $0.001\left(^{* * *}\right)$.

spermatogenesis. By combing phosphoproteome with bioinformatics analysis, we showed that the phosphorylation status of $\beta$-catenin at S552 was significantly upregulated in cKO group. $\beta$-catenin abnormal accumulation resulted in impaired testicular junction integrity, thus led to the abnormal structures and functions of BTB. Thus, our work for the first time reveals a novel role of PPP6C in determining germ cell death and differentiation by regulating the cell-cell communication through dephosphorylating $\beta$-catenin at $\mathrm{S} 552$.

\section{RESULTS \\ Specific deletion of Ppp6c gene by $A M H-C r e$ results in male infertility}

We gained mice in which the Ppp6c gene was specifically deleted in Sertoli cells to study the PPP6C functions in Sertoli cells. We used $P p p 6 c^{F / F}$ mice in which exons II-IV of the Ppp6c gene were flanked with Loxp sites [22]. PPP6C was disrupted in Sertoli cells by crossing $P p \sigma^{F / F}$ mice with $A M H$-Cre transgenic mice (referred to as Ppp6cko) (Fig. 1A). AMH-Cre recombinase had recombinase activities in Sertoli cells [23]. PPP6C-deletion efficiency in Sertoli cells was analyzed by testing the protein levels in Sertoli cells. The results (Fig. 1B) indicated that PPP6C was absent in Sertoli cells of Ppp6c ${ }^{C K O}$ mice. So, we gained Sertoli cell-specific knockout mice for PPP6C. The breeding assays indicated that the Ppp6c cKO mice were infertile (Fig. 1C, D).

\section{Ppp6c depletion causes abnormal spermatogenesis}

To determine the causes of infertility in $P p p 6 c^{c K O}$ mice, we firstly analyzed the histology of the epididymides by hematoxylin and eosin (H\&E) staining. The results showed that circular-cellular debris rather than mature spermatozoa were commonly found in the epididymal lumens of Ppp6c ${ }^{c K O}$ mice (Fig. 2A). In particular, large numbers of what appear to be highly vacuolated round cells were observed in the epididymides of $P p p 6 c^{c K O}$ males. And these circular cells diminished with age (Fig. S1A). Then, we performed immunofluorescence staining of the DAPI to characterize the shape of sperm in epididymal lumens. The results revealed that the shape of sperm in Pppбc ${ }^{W T}$ was hook-like, but the shape of sperm in $P p p 6 c^{C K O}$ was round (Fig. S2A), suggesting that the process of spermatogenesis was affected in $P p p 6 c^{c K O}$ mice. Also, we found that the majority of $P p p 6 c^{c K O}$ germ cells in epididymal lumens were not typical haploid (Fig. 2B). We speculated that germ cells were undergoing apoptosis. So, we performed TUNEL assay and found that germ cells underwent apoptosis in the Ppp6c ${ }^{c K O}$ mice (Fig. 2C). Then we found the testes of Ppp6c ${ }^{c K O}$ mice were much smaller than controls (Fig. $3 \mathrm{~A}$ ) and the testis weight to body weight ratio of $P p p 6 c^{c K O}$ was lower (Fig. 3B). And the variations of testes were more drastic with age (Fig. S3A, B). Also, compared with controls, the number of germ cells were sharply reduced, and there are nearly no round and elongated spermatids in Ppp6c ${ }^{c K O}$ mice (Fig. 3C). And the variations of histomorphology were more distinct with age (Fig. S3C). Similarly, we performed TUNEL assay to detect apoptosis. The results showed that germ cells underwent apoptosis in the Ppp6 ${ }^{c K O}$ mice (Fig. 3D).

According to the above results, we discovered that Ppp6c depletion causes impaired spermatogenesis and the number of germ cells were reduced. To confirm the results, we performed immunofluorescence by using the germ cell marker $\mathrm{MVH}$. Immunofluorescence results indicated that the number of MVH positive signals was decreased in Ppp6c ${ }^{c K O}$ testicular sections compared with those in $P p p 6 c^{W T}$ (Fig. 4A). Then we wanted to know whether it influenced the Sertoli cells in PPP6C null males. We performed immunofluorescence by using the Sertoli cells marker SOX9. The results showed that the number and location of Sertoli cells did not show the obvious change (Fig. 4B).

As the spermatogenesis was disturbed in $P p p 6 c^{c K O}$ mice, we hope to determine which stages of spermatogenesis were affected in PPP6C cKO mice. Spermatogenesis can be subdivided into 12 stages and 16 steps in mouse testes by combining PNA lectin with DAPI [24, 25]. Also, we could determine different cell types in each phase by using IHC for PLZF, SYCP3, and SOX9, markers for type A spermatogonia, spermatocytes, and Sertoli cells, respectively. We found that spermatogenesis of PPP6C-deficient mice was blocked at stages VII-VIII (step 7-8 spermatids) (Fig. 5A, B). Then we quantified the cell numbers in seminiferous tubules and found that the 
A

$40 X$
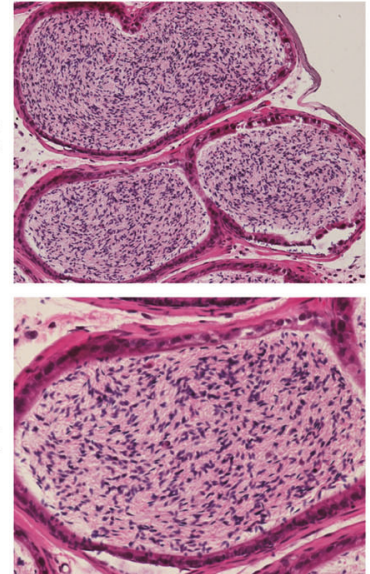

$P p p 6 c^{W T}$
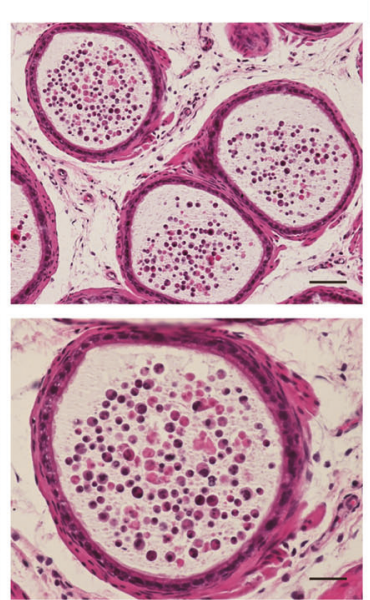

$P p p 6 c^{c K O}$

B

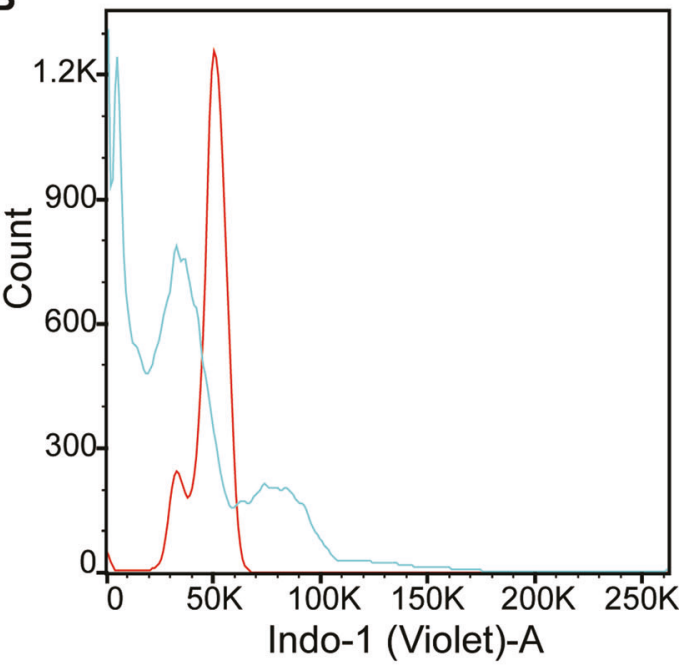

C

$20 X$
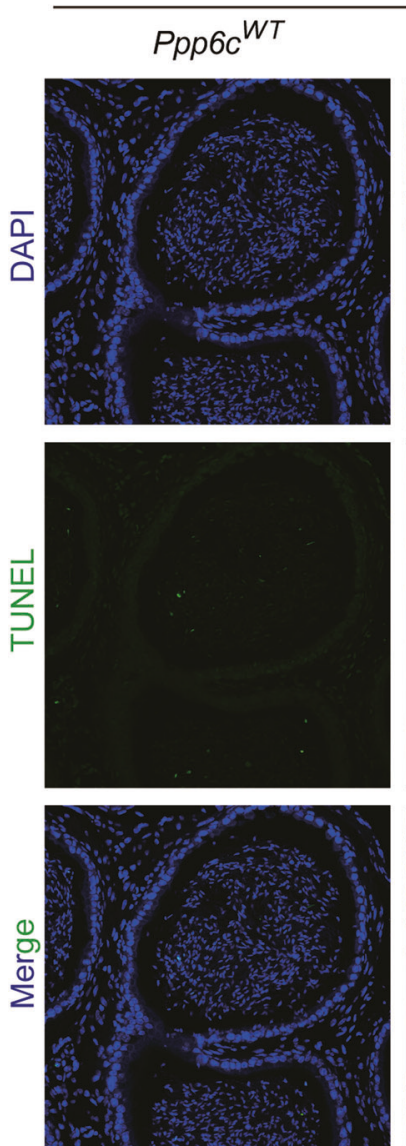

$P p p 6 c^{c K O}$
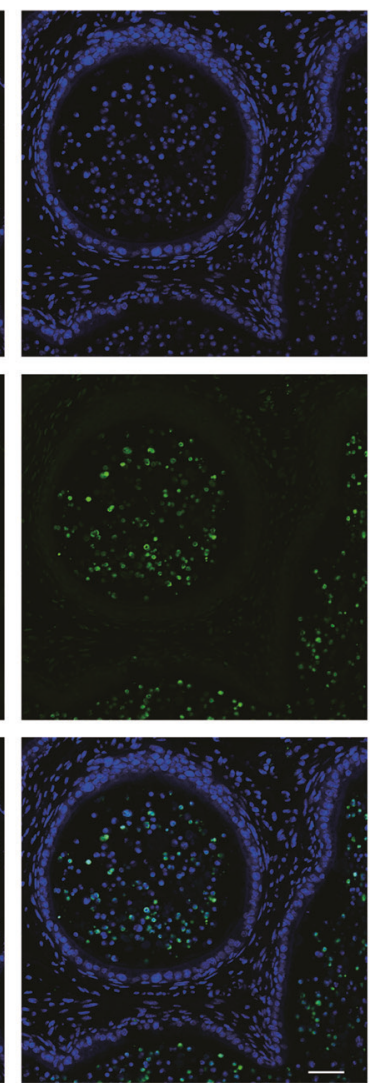

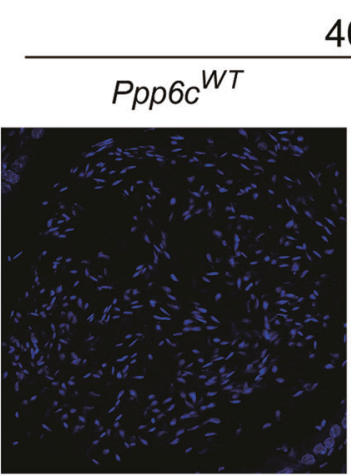

$40 X$
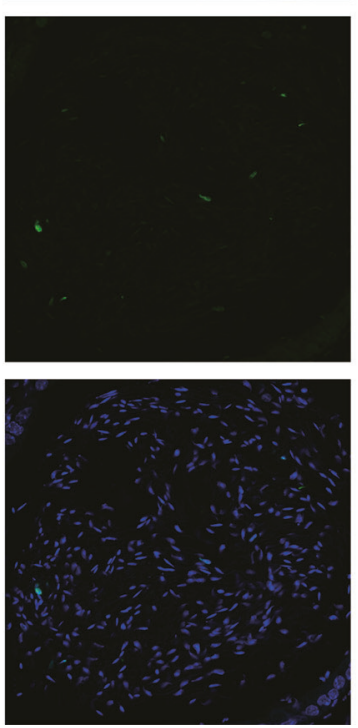
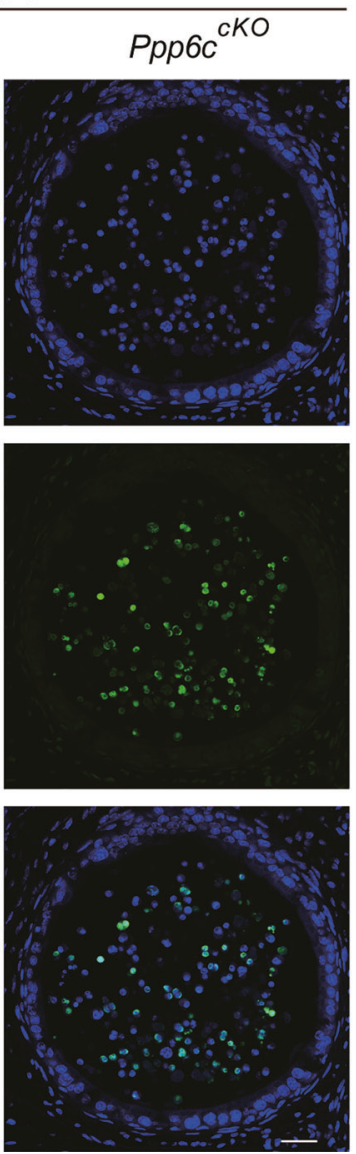

Fig. 2 PPP6C is required for spermatogenesis. A Histological analysis of the caudal epididymides of the Ppp6c $c^{W T}$ and $P p p 6 c^{c K O}$ mice. Scale bar: (top) $100 \mu \mathrm{m}$; (bottom) $50 \mu \mathrm{m}$. B DNA content analysis of control and cKO cells derived epididymides by FACS. The red peak represents the control, which had normal haploid DNA contents; while the blue peak represents the Ppp6c ${ }^{c K O}$ cells derived epididymides, which were abnormal. C TUNEL immunofluorescence staining of the epididymides of $P p p 6 c^{W T}$ and $P p p 6 c^{c K O}$. Scale bar: (left) $50 \mu \mathrm{m}$, (right) $20 \mu \mathrm{m}$. Green: TUNEL positive signal; Blue: DAPI. At least 3 mice (8-week-old) of each genotype were used for analysis.

numbers of type In spermatogonia, type B spermatogonia, leptotene spermatocytes/zygotene spermatocytes, pachytene spermatocytes/diplotene spermatocytes, round spermatids, as well as elongating spermatids were all reduced (Fig. $5 \mathrm{C}$ ). These data showed that Sertoli cell-specific PPP6C knockout results in spermatogenesis failure and thus male infertility.

\section{A large-scale quantification of the phosphoproteome in PPP6C null Sertoli cells}

To investigate a comprehensive perspective of the mechanisms of PPP6C depletion in Sertoli cells, we isolated them from Ppp6c ${ }^{W T}$ and $P p p 6 c^{C K O}$ testes at 5-7 dpp and systematically profiled the quantitative phosphoproteome (Fig. 6A). We applied a 4D 
A
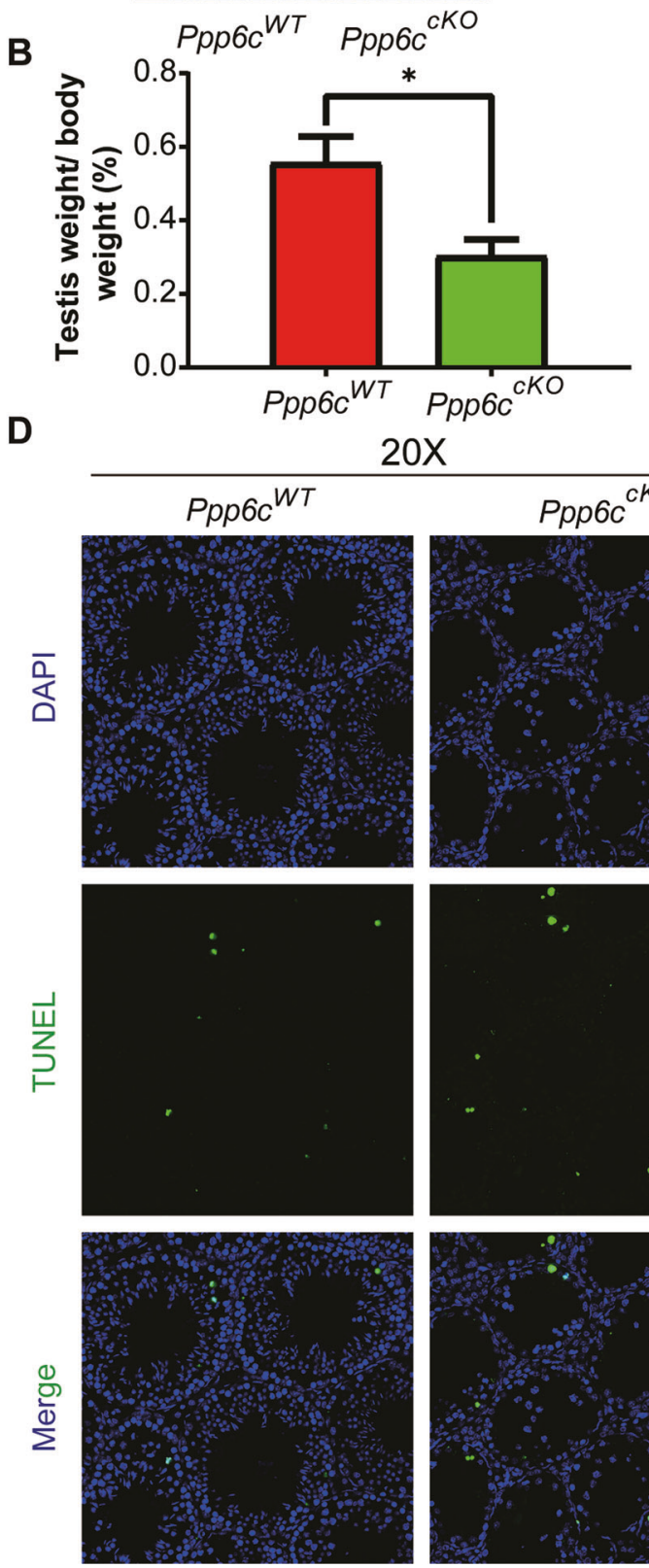

C
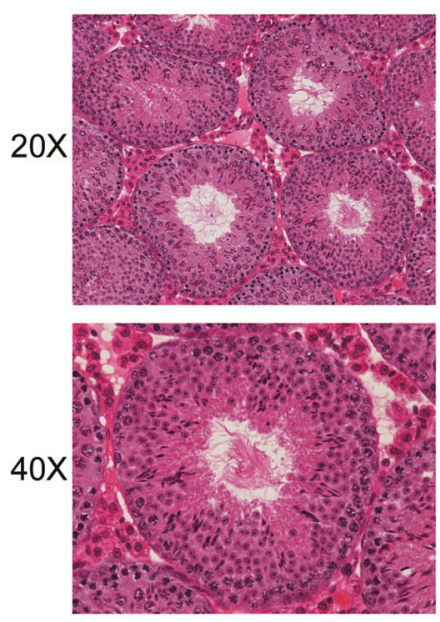

$P p p 6 c^{W T}$
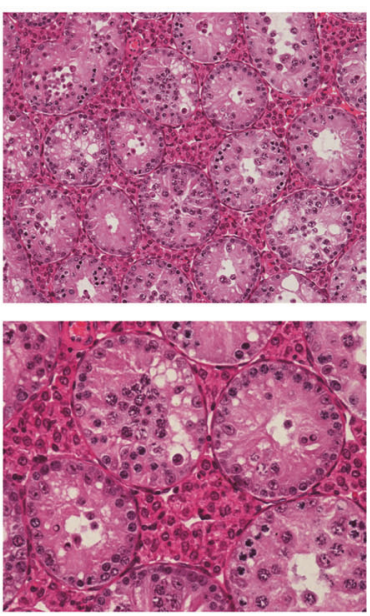

Pрp6c ${ }^{c K O}$

$40 \mathrm{X}$
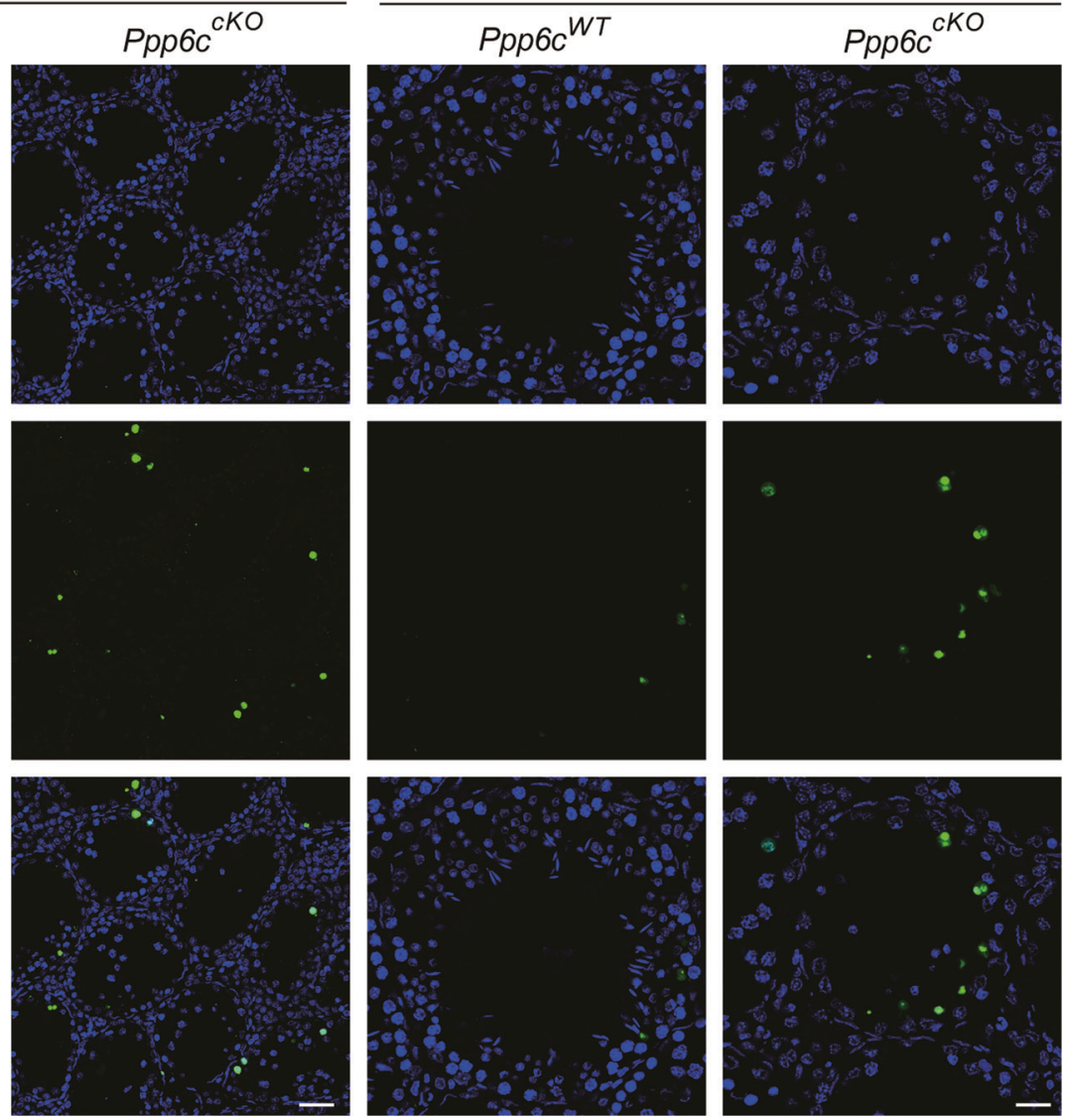

Fig. 3 PPP6C knockout in mouse Sertoli cells by AMH-Cre results in testicular atrophy and the apoptosis of germ cells. A The testes of $P p p 6 c^{c K O}$ were smaller than those of the Ppp6c ${ }^{W T}$ (8-week-old, the same as below). B Testis weight to body weight ratio of Ppp6c ${ }^{W T}$ and Ppp6c ${ }^{c K O}$ mice $(n=3)$. Data are presented as the mean \pm SEM. $P<0.05\left(^{*}\right), 0.01\left(^{* *}\right)$ or $0.001\left(^{* * *}\right)$. C Histological analysis of the seminiferous tubules of the $P p p 6 c^{W T}$ and $P p p 6 c^{c K O}$ mice. Scale bar: (top) $100 \mu \mathrm{m}$; (bottom) $50 \mu \mathrm{m}$. D TUNEL immunofluorescence staining of the testes of $P p p 6 c^{W T}$ and Ppp6c ${ }^{c K O}$. Scale bar: (left) $50 \mu \mathrm{m}$, (right) $20 \mu \mathrm{m}$. Green: TUNEL positive signal; Blue: DAPI. At least 3 mice (8-week-old) of each genotype were used for analysis.

label-free quantification approach by high-resolution liquid chromatography-mass spectrometry (LC-MS) [26]. In total, we identified 16,190 unique peptides and 12,476 of them were modified peptides. By mapping the phosphopeptides to their corresponding protein sequences, we comprehensively quantified 2965 phosphoproteins with 7339 unique phosphorylation sites (Fig. 6B). Among these quantified phosphoproteins and phosphorylation sites, we defined significantly different $(p<0.05$ by Student's $t$ test) proteins and used a criterion of 1.5-fold change or greater between these two groups as differential protein candidates. Subsequently, 788 downregulated proteins and 1449 upregulated proteins were identified. Similarly, 1188 downregulated phosphorylation sites and 2672 upregulated phosphorylation sites in were identified (Fig. 6C). To obtain more 
A
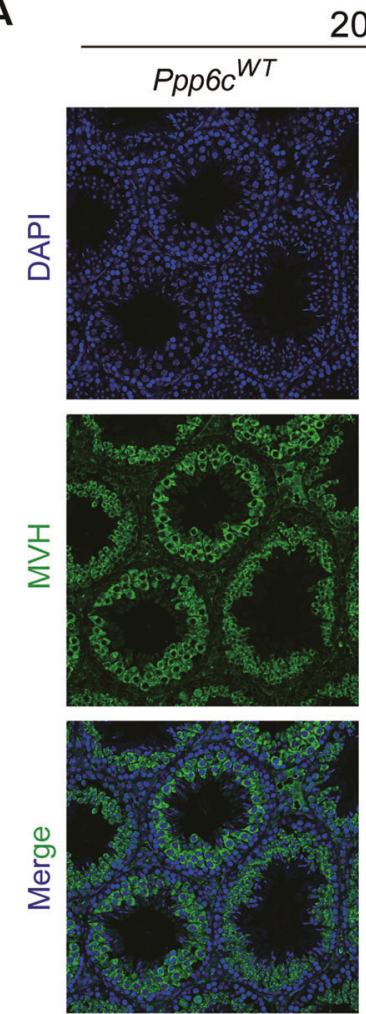

B
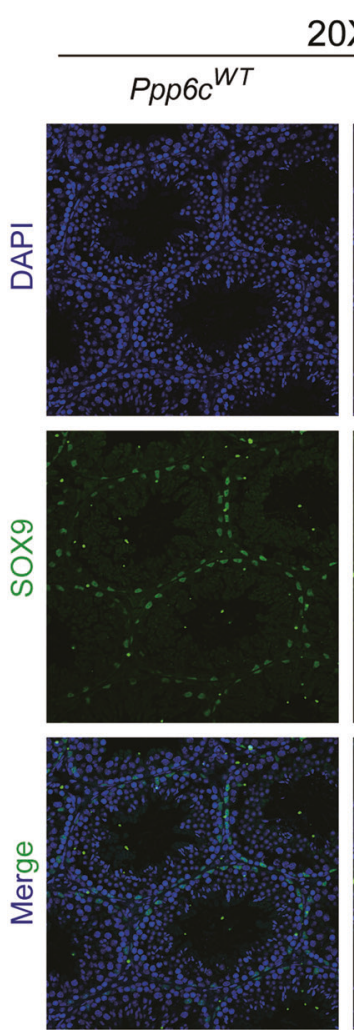

$20 X$

$P_{p p 6 c}{ }^{c K O}$
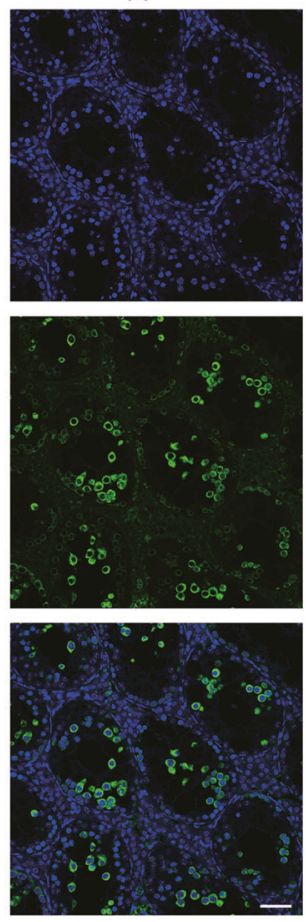

$20 X$

$P p p 6 c^{c K O}$
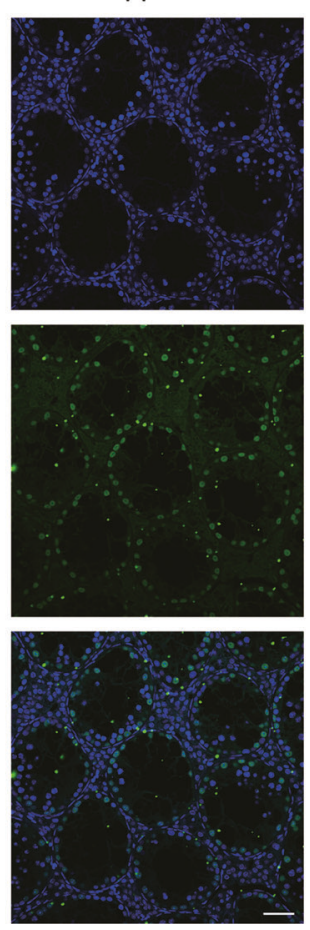
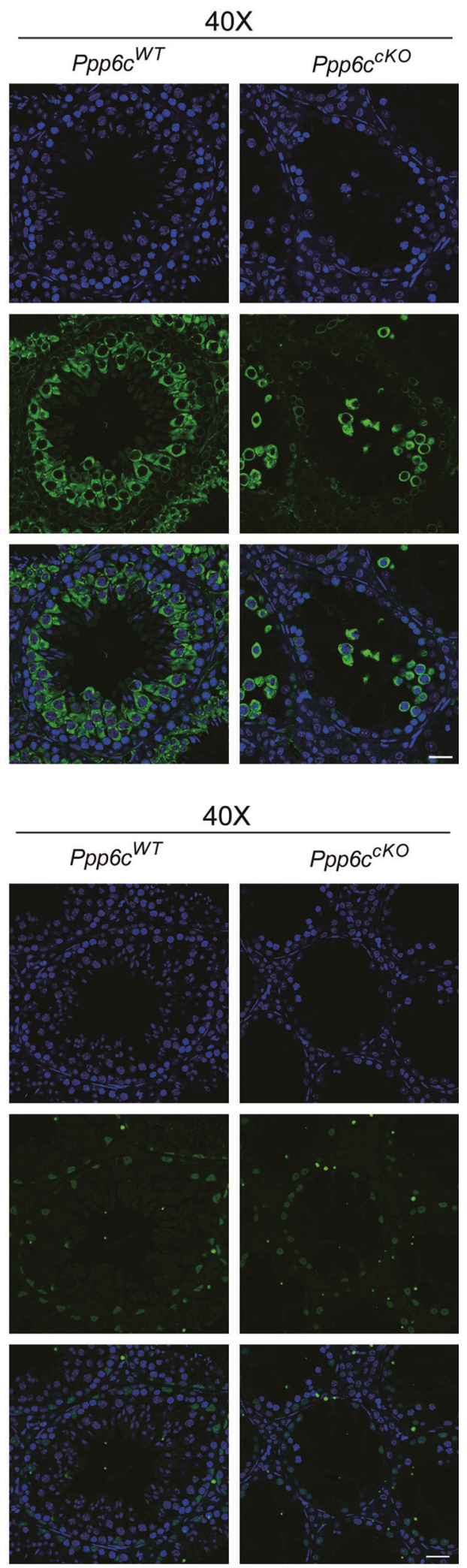

Fig. 4 PPP6C knockout in mouse Sertoli cells by $A M H$-Cre results in the loss of germ cells. A MVH (green) immunofluorescence analysis of the $P p p 6 c^{W T}$ and $P p p 6 c^{C K O}$ mice showed that the amount of the germ cells were decreased Scale bar: (left) $50 \mu \mathrm{m}$, (right) $20 \mu \mathrm{m}$. (B) SOX9 (green) immunofluorescence analysis of the $P p p 6 c^{W T}$ and $P p p 6 c^{c K O}$ mice showed that the amount and location of the Sertoli cells were similar. Scale bar: (left) $50 \mu \mathrm{m}$, (right) $20 \mu \mathrm{m}$. Nuclei are stained with DAPI. At least 3 mice of each genotype were used for analysis. 
A
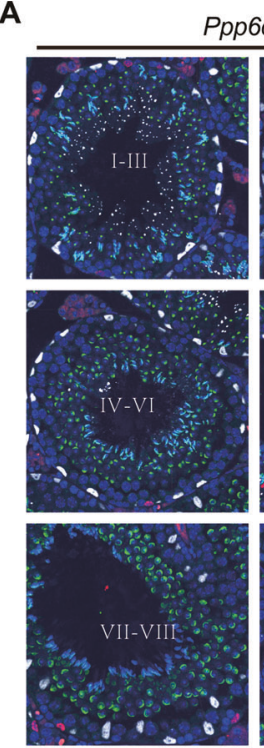

$P p p 6 c^{W T}$
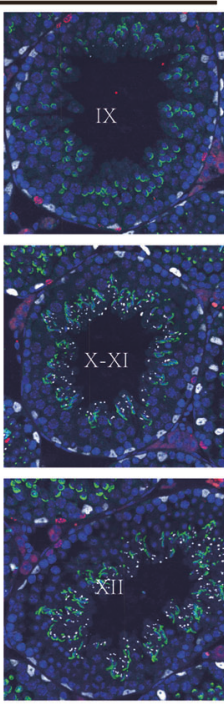

B

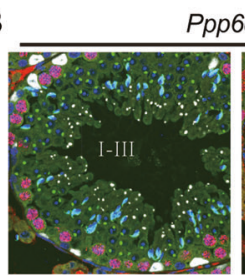

Ppp6c WT
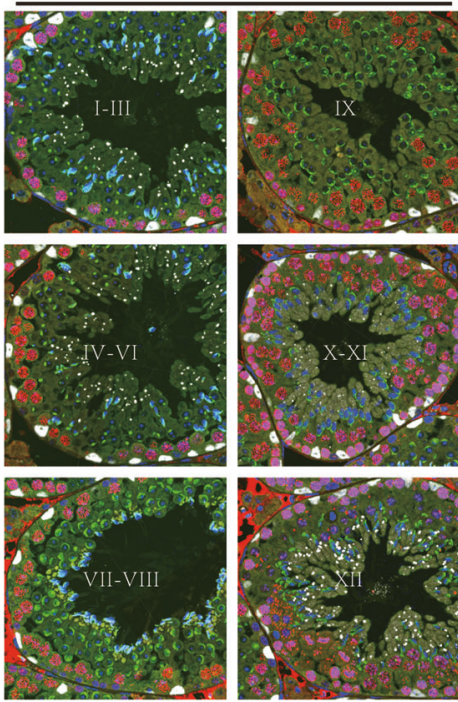

C

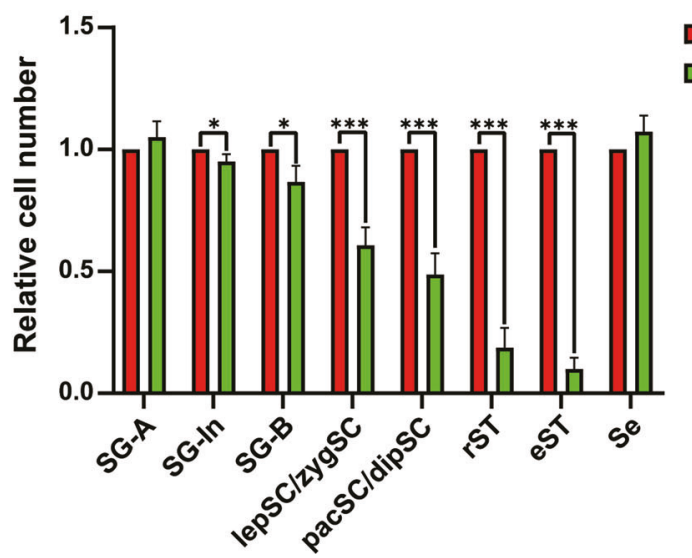

$P p p 6 c^{c K O}$

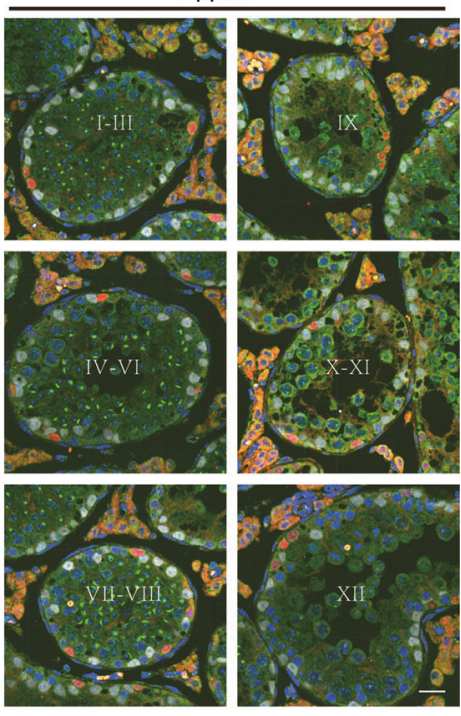

$P_{p p 6 c}{ }^{c K O}$

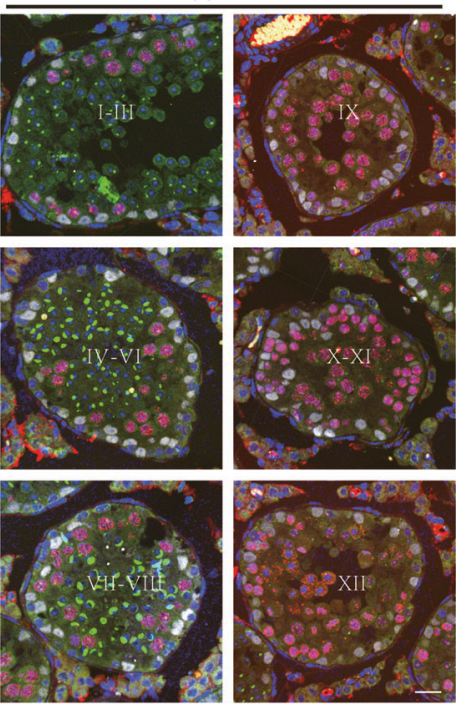

Ppp6c
Ppp $6 \mathrm{c}$ cKO comprehensive information, we then performed Gene Ontology (GO) annotation. These proteins were sorted by Gene Ontology annotation based on: biological process, cellular component, and molecular function. GO analysis of upregulated proteins showed that 576 proteins were related to the processes of development (Fig. 6D), and GO analysis of downregulated proteins showed that
307 proteins were related to the processes of development (Fig. 6E). Then, we performed these proteins to bioinformatics enrichment analysis with GO and KEGG databases. These analyses revealed that these differential proteins were closely involved in adherens junctions, tight junctions, cell junction, and microtubule (Fig. S4), suggesting PPP6C could be important in cell connection 
Fig. 5 Ppp6c cKO mice arrest spermatogenesis at step 7-8 spermatids. A Determination of stages (I-XII) and identification of cell types using a combination of IHC and PNA-lectin histochemistry. Three- $\mu$ m-thick sections were double-immunostained for PLZF (red) and SOX9 (white), then stained with PNA-lectin histochemistry (green) and DAPI (blue). Scale bar: $10 \mu \mathrm{m}$. B Determination of stages (I-XII) and identification of cell types using a combination of IHC and PNA-lectin histochemistry. Three- $\mu$ m-thick sections were double-immunostained for SYCP3 (red) and SOX9 (white), then stained with PNA-lectin histochemistry (green) and DAPI (blue). Scale bar: $10 \mu \mathrm{m}$. C Quantification of spermatogenic cell types in $P p p 6 c^{W T}$ and $P p p 6 c^{c K O}$ mice based on the images shown in A-B. For each cell type, at least 150 tubules from three mice were counted. The average numbers of cells per tubule were converted to ratios and compared between $P p p 6 c^{W T}$ and $P p p 6 c^{C K O}$ mice. SG-A, type A spermatogonia; SG-In, type In spermatogonia; SG-B, type B spermatogonia; lepSC/zygSC leptotene spermatocytes/zygotene spermatocytes, pacSC/dipSC pachytene spermatocytes/diplotene spermatocytes, rST round spermatids, eST elongating spermatids, Se Sertoli cells.

and multiple cellular signaling regulation. Together, the phosphoproteome in PPP6C null Sertoli cells analysis suggested multiple new roles of PPP6C in cellular physiology, especially in cell communication and cell connection.

\section{Testicular junction integrity is impaired in Ppp6c ${ }^{\text {cko }}$ testes} According to the above-presented phosphoproteome data, we found that these differential phosphorylated proteins were closely related in cell junction and communication. Because of the loss of germ cells and the analyses of phosphoproteome data in Ppp6c ${ }^{c k o}$ testes, we speculated that testicular junction integrity is impaired in PPP6C null mice. To verify the hypothesis, we firstly analyzed the expression of AJ ( $\beta$-catenin) and TJ [zonula occludens 2 (ZO-2)] proteins in control and mutant testes. $\beta$-catenin was occured in the basal and lower adluminal compartment of control (Fig. 7A). Similar to $\beta$-catenin expression, ZO-2 was also occured in the basal compartment in WT testes (Fig. 7B). In contrast, mislocalization of $\beta$-catenin and ZO-2 was occured in Ppp6c ${ }^{c K O}$ mice (Fig. 7A, B). The testis-expressed gene 14 (TEX14), is mainly occurred in germ cell intercellular bridges and it is essential for spermatogenesis [27]. We found that mislocalization of TEX14 and $\beta$-actin was present in Ppp6c ${ }^{C K O}$ testes by using immunofluorescence (Fig. 7C), suggesting defects in testicular junctional complexes.

Sertoli cells also are polarized cells that extend from the basement membrane to the lumen of seminiferous tubules [28]. The apical extensions of Sertoli cells are contact with germ cells, directing their migration towards the lumen of the seminiferous tubules. We examined Sertoli cell apical extensions (marked by Vimentin) and observed the loss of apical extensions (Fig. 7D). These data showed that PPP6C-deletion influence the integrity of $B T B$, finally resulting in the loss of germ cells.

\section{PPP6C directly dephosphorylates $\beta$-catenin}

To explore the mechanism underlying PPP6C-deletion-caused abnormal spermatogenesis, we analysed the detailed information on differential protein groups and p-sites (Supplementary Table 1) and found that the phosphorylation status of $\beta$-catenin at $\$ 552$ (a marker of adherens junctions) was significantly upregulated in cKO group. By using immunoblotting, we tested the phosphorylation level of $\beta$-catenin at S552 and found that the phosphorylation status of $\beta$-catenin at $S 552$ was significantly upregulated in cKO group (Fig. 8A), indicating that PPP6C could regulate the phosphorylation status of $\beta$-catenin. By using in vitro phosphatase assays, purified PPP6C (WT or D84N) was incubated with isolated CTNNB1 (Fig. 8B). As expected, we found an obvious elimination of phospho- $\beta$-catenin (S552) by PPP6C, but not by the phosphatasedead PPP6C (D84N) (Fig. 8C). All observations thus suggested that PPP6C could directly dephosphorylate $\beta$-catenin. Generally, phosphorylation of $\beta$-catenin results in a weakening of the cadherin- $\beta$-catenin interaction, directing $\beta$-catenin into signaling mode. A study suggested that the phosphorylation of $\beta$-catenin at Ser552 was related with nuclear accumulation and transcriptional activation [29]. Therefore, we tested the locations of $\beta$-catenin in Sertoli cells from $P p p 6 c^{W T}$ and $P p p 6 c^{c K O}$ testes by immunofluorescence and found the nuclear accumulation of $\beta$-catenin in cKO mice (Fig. 8D). These data suggested that PPP6C deletion caused the abnormal nuclear accumulation of $\beta$-catenin and weakened of the cadherin- $\beta$-catenin interaction.

\section{DISCUSSION}

PP6 is a member of the PP2A-like subfamily and has a functional role in mitosis $[19,30]$. Our lab previously reported that a conditional knockout of PPP6C in oocytes from growing follicles resulted in female subfertility, and a conditional knockout of PPP6C in oocytes from the primordial follicle stage, caused female infertility $[22,31]$. As for male, we found that PPP6C is also critical for fertility and germ cell meiosis [21].

Sertoli cells play a very important role in spermatogenesis. In the seminiferous epithelium, cell-cell communications are hold by Sertoli-germ cell junctions and Sertoli-Sertoli cell junctions. There are some other junctions besides the tight junctions, such as the desmosome-like junction and the ectoplasmic specialization (ES) $[32,33]$. At the early phase of the epithelial cycle, it is essential for the preleptotene spermatocytes to cross the BTB to enter the apical compartment and to get ready for meiotic progression by the disassembly and reassembly of the basal ES [32, 34]. During the procedures described above, BTB-related proteins, such as $\beta$-Catenin (a marker of adherens junctions), ZO2 (a marker of tight junctions), TEX14 (a marker of testicular intercellular junctions), and Vimentin (a marker for Sertoli apical extensions) play critical roles. In our study, we found that these proteins had abnormal expressions and locations in Ppp6c ${ }^{C K O}$ male mice. We speculated that the defects in testicular junctional complexes result in the abnormal structures and functions of BTB. Finally, PPP6C depletion causes male infertility and the loss of germ cells.

As one of the mostly characterized posttranslational modifications (PTMs), protein phosphorylation plays important roles in the adjustment of spermatogenesis. For the past few years, phosphoproteomic techniques have identified and quantified of thousands of phosphorylation sites in a single run [35, 36]. Although some large-scale studies have reported protein phosphorylation in different tissues and cells, the identification of critical regulatory protein phosphatase from the Sertoli cells of data has never been reported. To gain a comprehensive perspective of the mechanisms of PPP6C depletion in Sertoli cells, we isolated Sertoli cells from Ppp6c $c^{W T}$ and $P p p 6 c^{c K O}$ testes at 5-7 dpp and systematically profiled the quantitative phosphoproteome. The results showed that 788 downregulated proteins and 1449 upregulated proteins were identified. Similarly, 1188 downregulated phosphorylation sites and 2672 upregulated phosphorylation sites were identified. Then, we analysed and found that these differential proteins were closely involved in adherens junctions, tight junctions, cell junction, microtubule, suggesting PPP6C could be important in cell connection and multiple cellular signaling regulation. We also found that the phosphorylation status of $\beta$-catenin at S552 was significantly upregulated in CKO group, indicating PPP6C could regulate the phosphorylation status of $\beta$-catenin.

The multifunctional protein $\beta$-catenin has significant functions in both the canonical Wnt signaling pathway and intercellular adhesion. It is essential for lots of developmental processes $[37,38]$. $\beta$-catenin is a member of the cadherin/catenin complexes. At adherens junctions, newly synthesized $\beta$-catenin is controled 
A

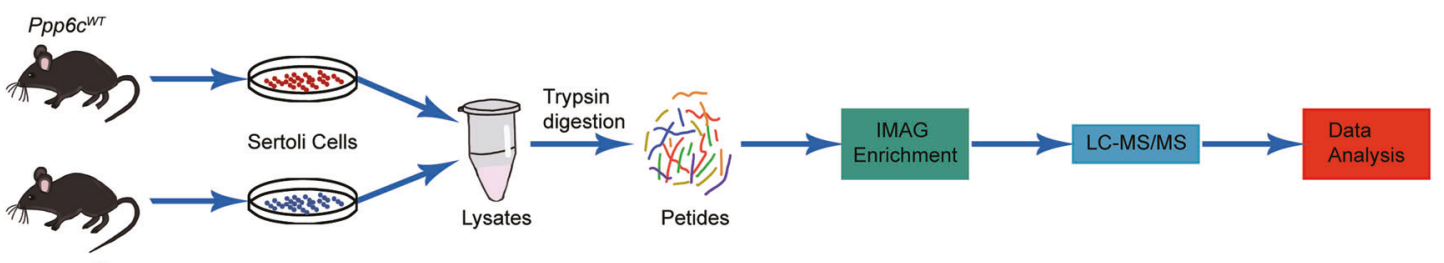

B

Ppp6c cko

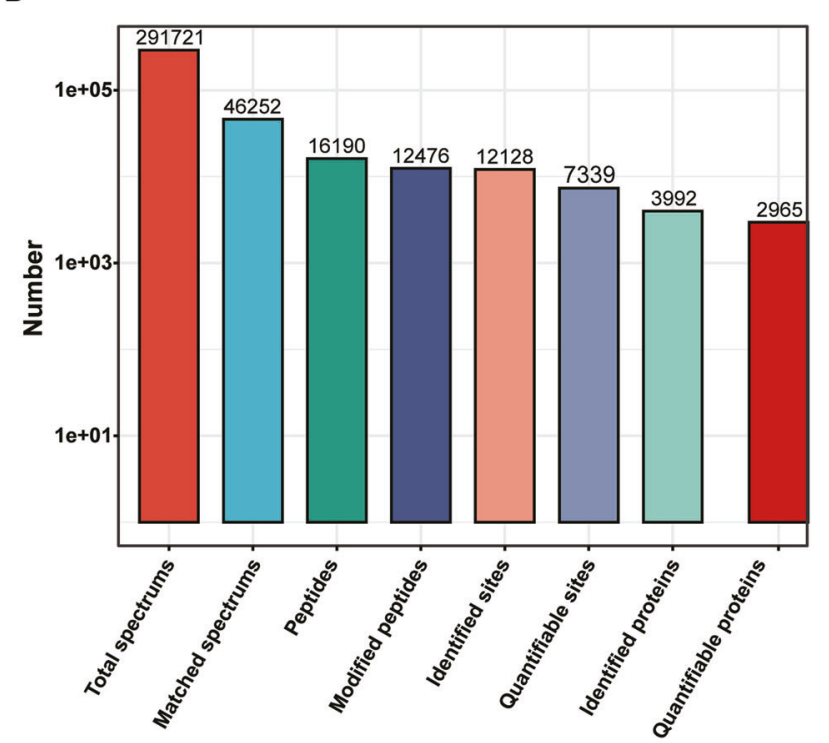

C

$\mathrm{D}$

GO-classify-Up regulated
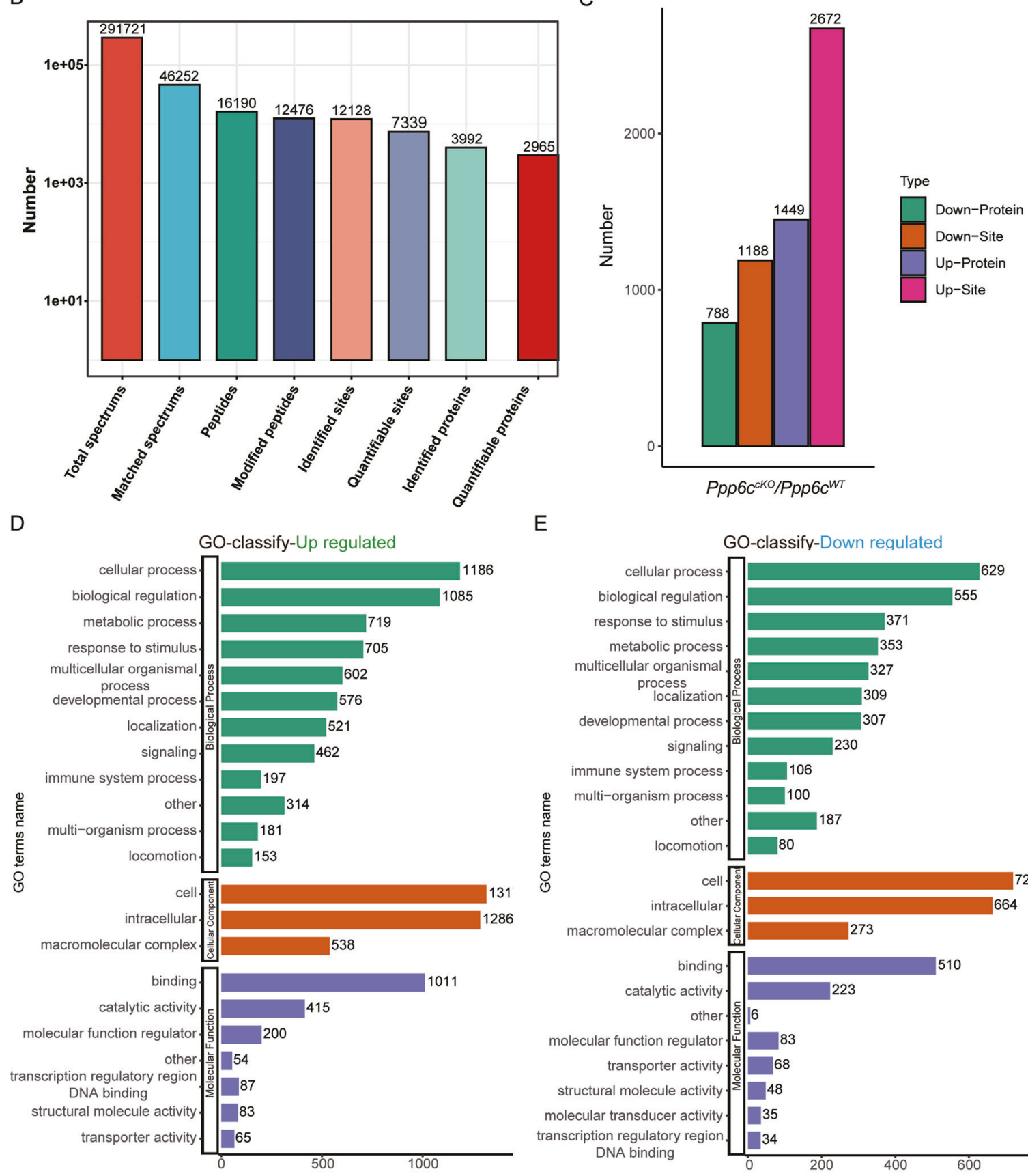

E

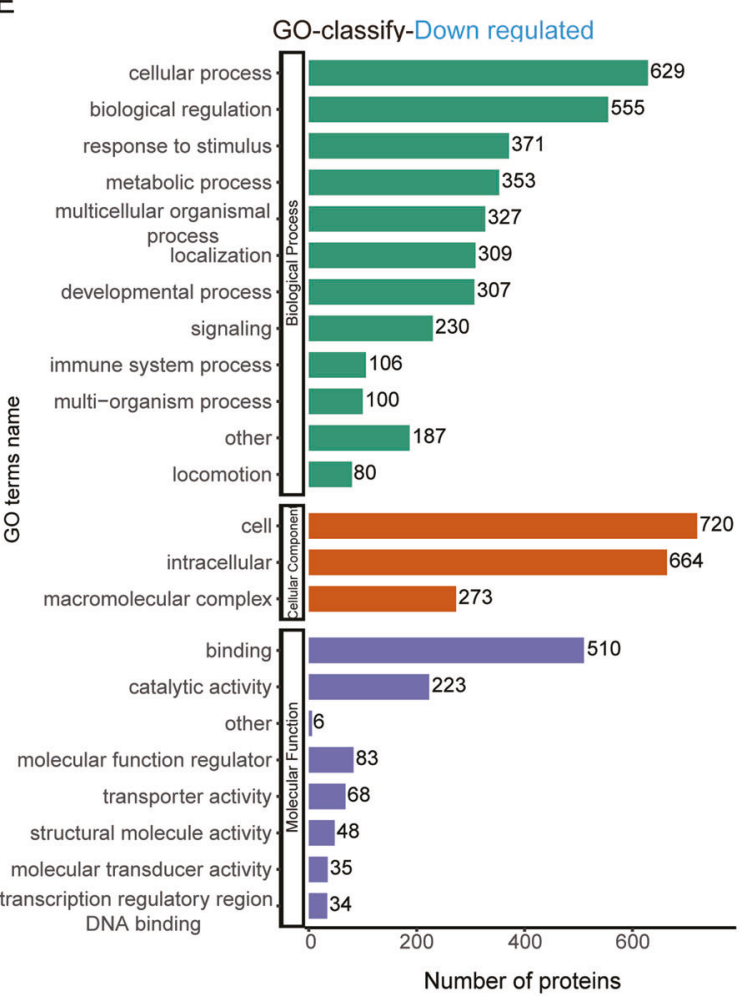

Fig. 6 Global analysis of quantitative phosphoproteome. A Flowchart of the identification of the quantitative phosphoproteome in $P p p 6 c^{W T}$ and $P p p 6 c^{C K O}$ mice Sertoli cells. B The resulting MS/MS data were processed using MaxQuant search engine (v.1.6.6.0). A summary of the identified and quantified phosphoproteome and $\mathrm{p}$-sites. $\mathbf{C}$ The number of up- and downregulated proteins and $\mathrm{p}$-sites in this study. D GO analysis of the significantly upregulated proteins for biological process, molecular function, and KEGG pathway. E GO analysis of the significantly downregulated proteins for biological process, molecular function, and KEGG pathway. 
A
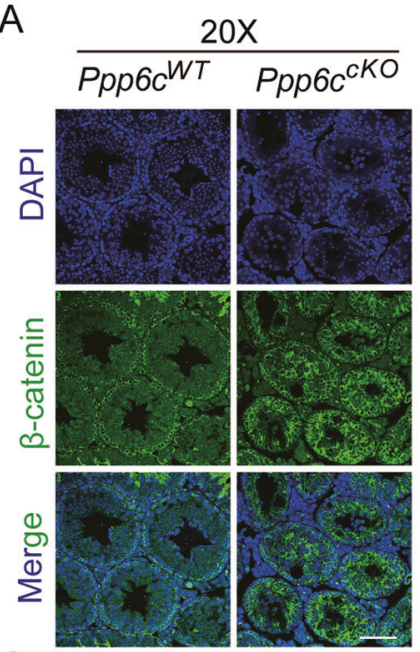

C
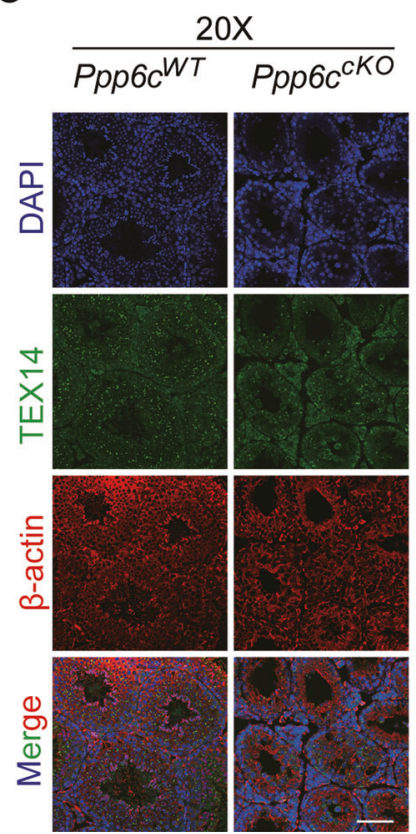

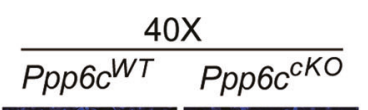

B
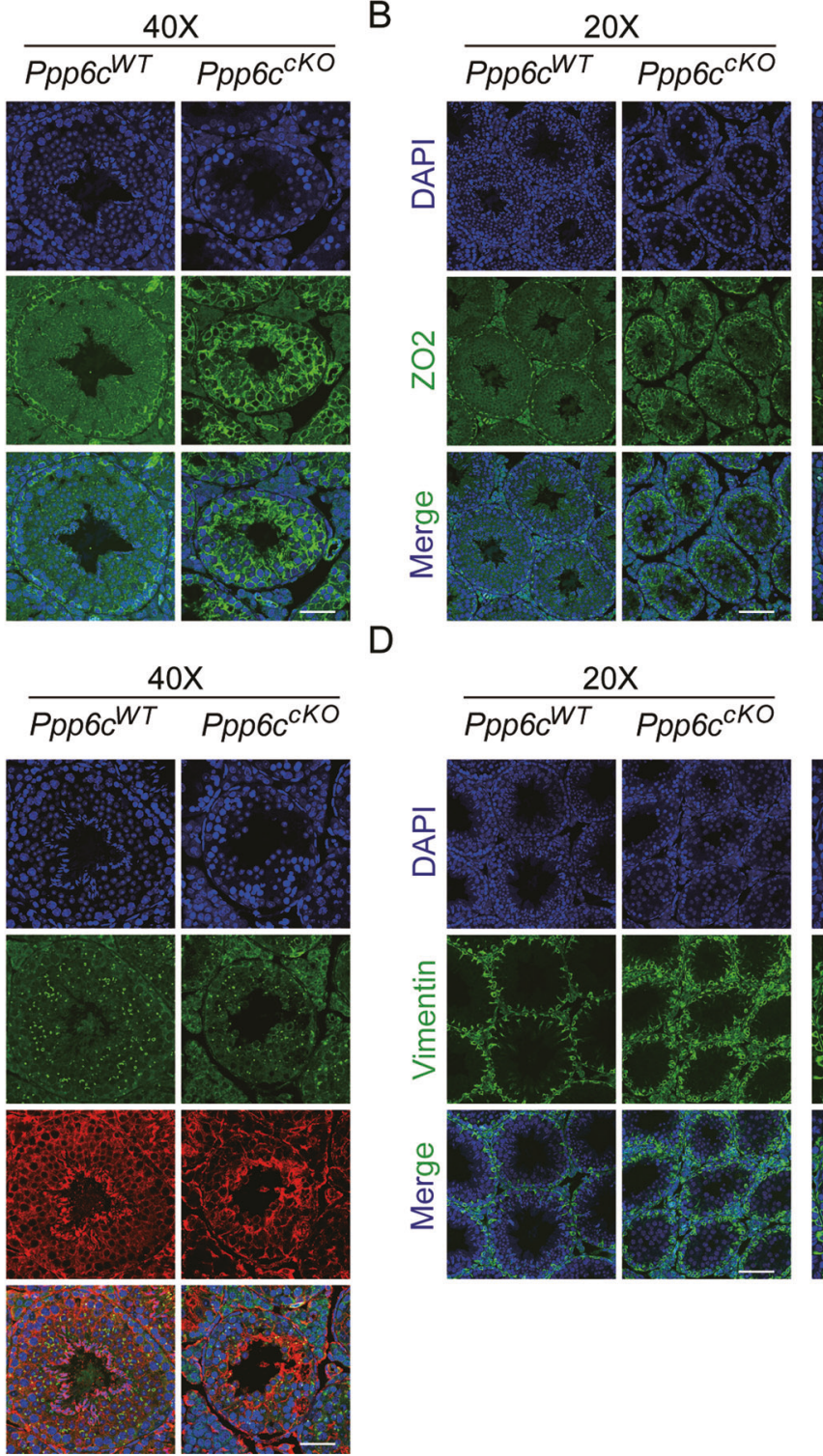

D
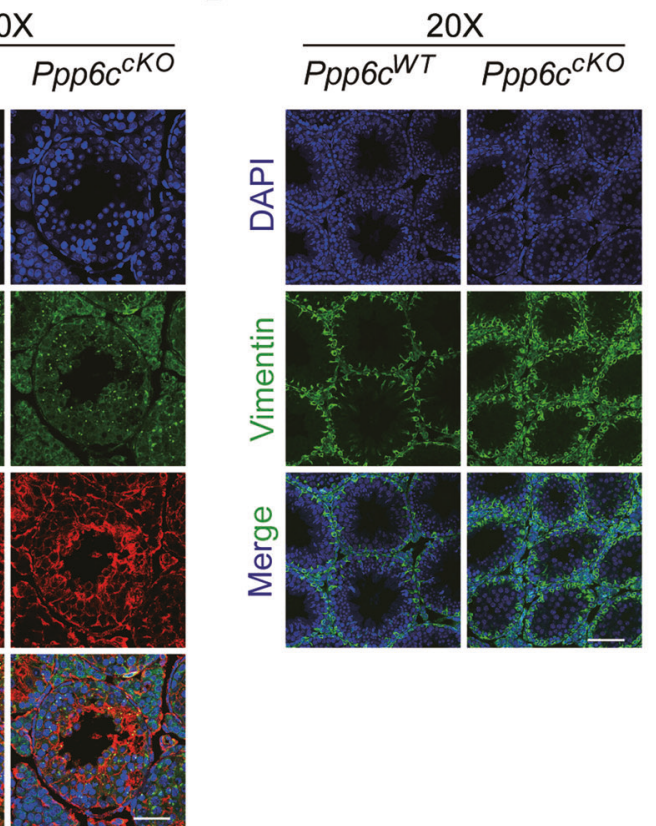
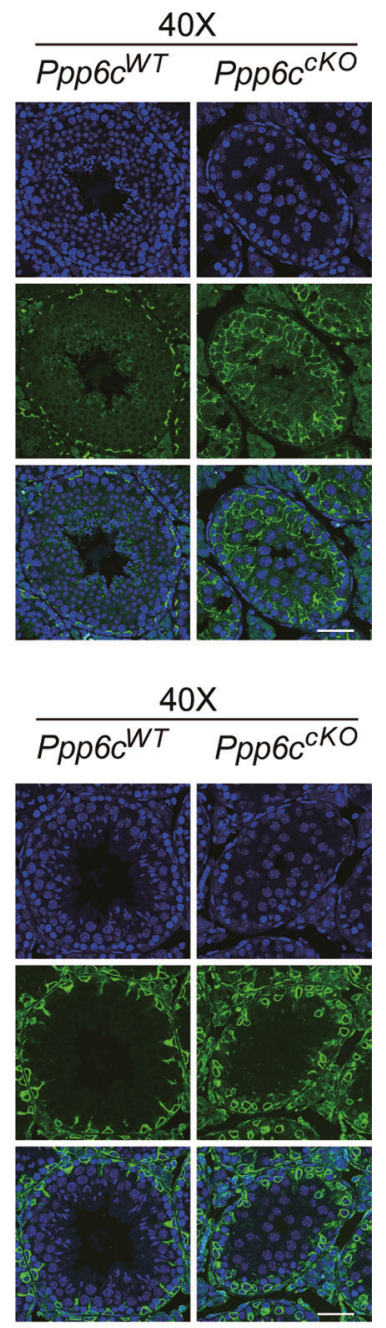

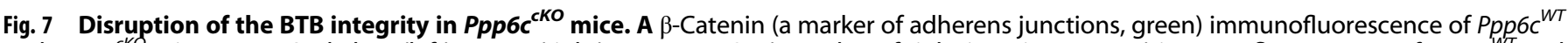

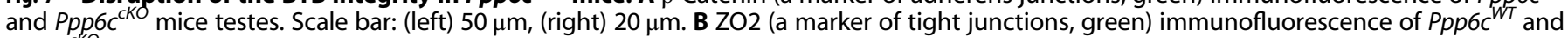

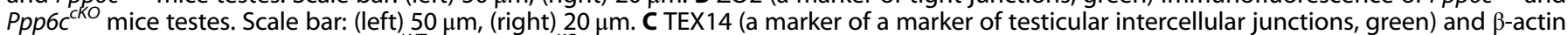
(red) immunofluorescence of $P p p 6 c^{W T}$ and $P p p 6 c^{c K O}$ mice testes. Scale bar: (left) $50 \mu \mathrm{m}$, (right) $20 \mu \mathrm{m}$. D Vimentin (a marker for Sertoli apical

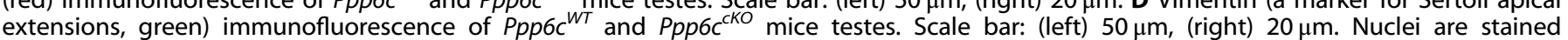
with DAPI.

by E-cadherin, thereby controlling the actin cytoskeleton [39]. As for the canonical pathway, in the absence of Wnt, $\beta$-catenin can be degraded by the destruction complex, which is composed of the casein kinase 1 (CK1), scaffolding protein Axin, glycogen synthase kinase 3 (GSK3) and the tumor suppressor adenomatous polyposis coli gene product (APC). CK1a can phosphorylate $\beta$-catenin at serine 45 and GSK3 can phosphorylate $\beta$-catenin at threonine 41 , serine 37 , and serine 33 by GSK3. The E3 ubiquitin ligase $\beta$-Trcp can bind $\beta$-catenin at serine 33 and 37 when the two sites were phosphorylated, finally leading to $\beta$-catenin ubiquitination and degradation [40]. APC has a critical role in ensuring the ubiquitin conjugation of phosphorylated $\beta$-catenin. In the absence of APC, PP2A can dephosphorylated $\beta$-catenin [41]. This successive elimination of $\beta$-catenin protects $\beta$-catenin from entering the nucleus. The nuclear accumulation of $\beta$-catenin is a symbol of activated canonical Wnt/ $\beta$-catenin signaling [42]. Active Wnt signaling destroys the destruction complex and induces the accumulation of $\beta$-catenin, which travels to the nucleus to interact with TCF/LEF and activates the transcriptional activity of Wnt target gene [43].

Generally, phosphorylation of $\beta$-catenin results in an instability of the $\beta$-catenin-cadherin complexs and direct $\beta$-catenin into signaling mode. A study suggested that the phosphorylation of $\beta$-catenin at Ser552 was related with nuclear accumulation and transcriptional activation [29]. Chang et al. reported that $\beta$-catenin was occurred in Sertoli cells especially in cell membrane. cKO of $\beta$-catenin in Sertoli cells by $A M H$-Cre caused no detectable abnormalities, whereas activation caused severe phenotypes, such as germ cell depletion and testicular cord disruption [44]. Other investigations found that activation of $\beta$-catenin in Sertoli cells by Amhr2-Cre resulted in male infertility and the loss of germ cells $[45,46]$. In our present study, we found that the phenotypes in Ppp6c ${ }^{c K O}$ mice are similar to those of previously reported conditional activated allele of the $\beta$-catenin in Sertoli cells by 
A

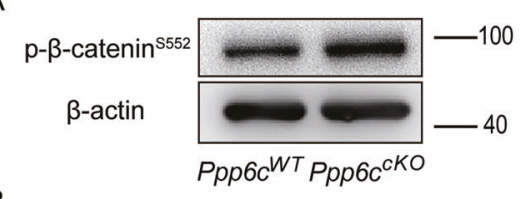

B
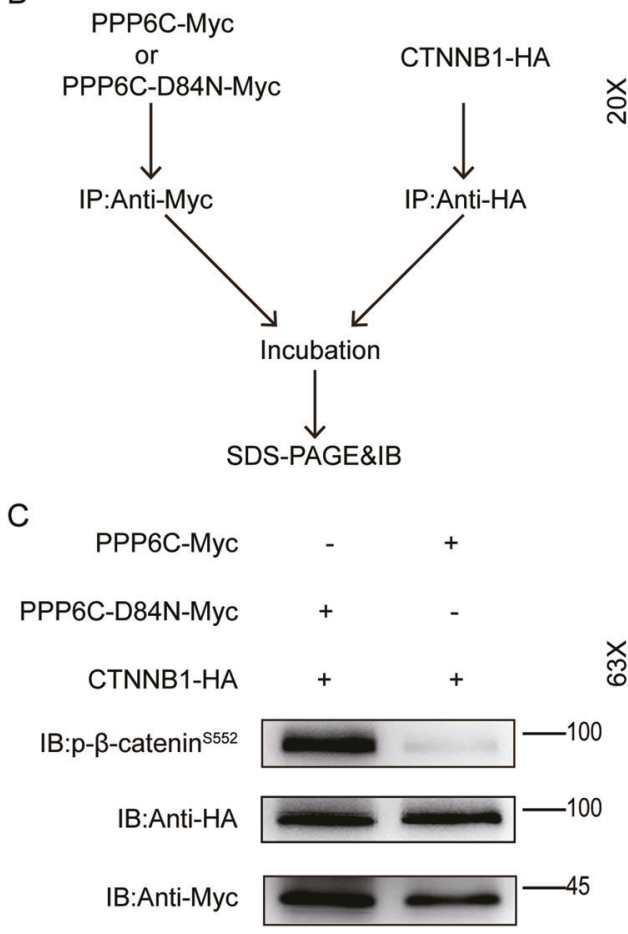

D
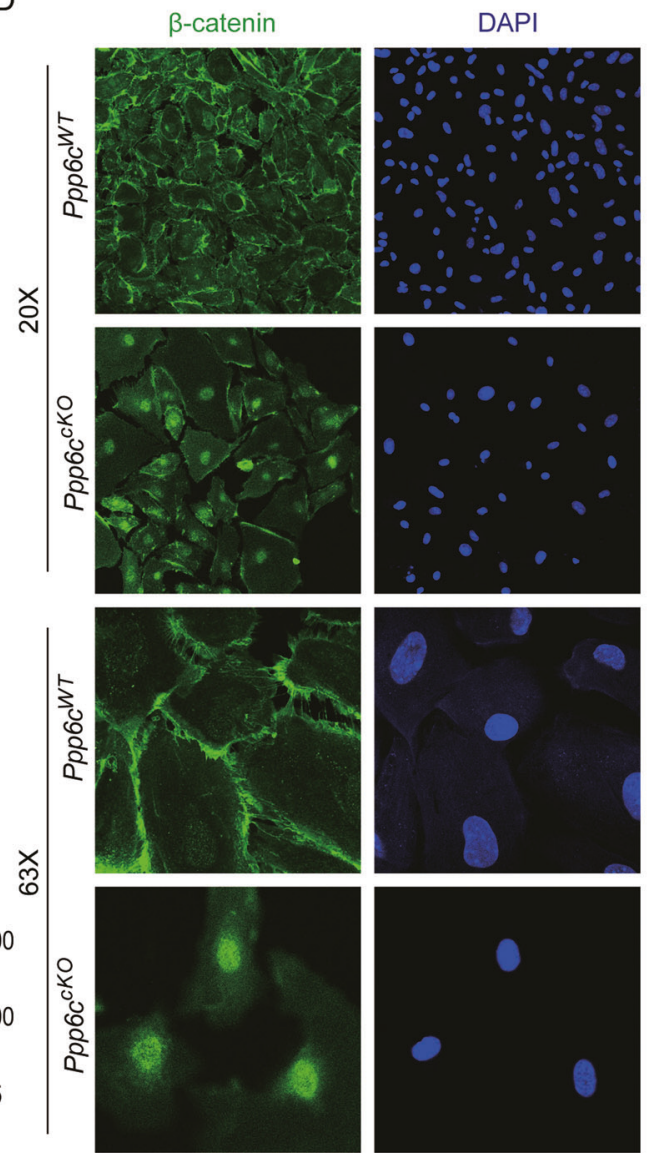
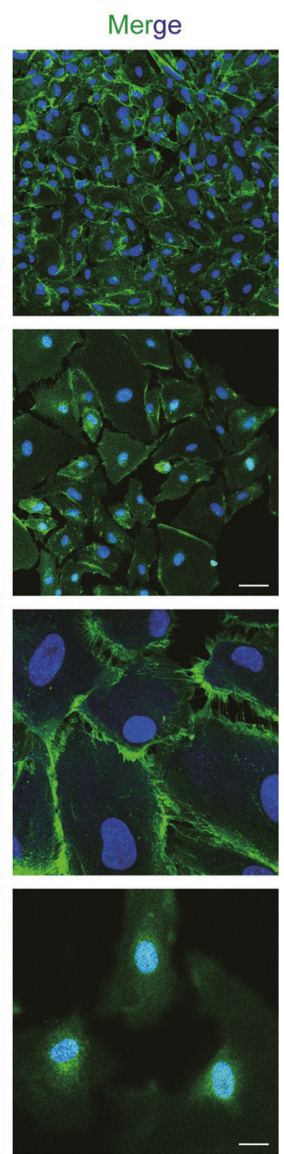

Fig. 8 PPP6C directly dephosphorylates $\boldsymbol{\beta}$-catenin. A Western blotting analysis of $\mathrm{p}-\boldsymbol{\beta}$-catenin ${ }^{\mathrm{S552}}$ protein in $P p p 6 c^{W T}$ and $P p p 6 c^{c K O}$ Sertoli cells of mice. $\beta$-actin was detected as an internal control. At least 3 mice of each genotype were used for analysis. B A schematic diagram of in vitro phosphatase assays which were performed by using purified PPP6C (WT or D84N) and CTNNB1. C PPP6C (WT or D84N) was incubated with CTNNB1 to perform the in vitro phosphatase assays. Immunoblotting of the assay products exhibited an effective elimination of phospho- $\beta$-catenin (S552) by PPP6C, but not by the phosphatase-dead PPP6C (D84N). D $\beta$-Catenin immunofluorescence of Ppp6c ${ }^{W T}$ and Ppp6c ${ }^{c K O}$ Sertoli cells of mice. Scale bar: (top) $50 \mu \mathrm{m}$, (bottom) $10 \mu \mathrm{m}$.

using $\mathrm{AMH}$-Cre or Amhr2-Cre by transgenic mouse, including male infertility and the loss of germ cells. We might provide new evidence to show that specific deletion of Ppp6c gene by $\mathrm{AMH}-\mathrm{Cre}$ increases the phosphorylation status of $\beta$-catenin at S552. Phosphorylation of $\beta$-catenin results in an instability of the $\beta$-catenin-cadherin complexs and the integrity of BTB, directing $\beta$-catenin into signaling mode, finally resulting in the loss of germ cells and male infertility.

\section{MATERIALS AND METHODS \\ Mice}

Mice with disrupted $P p p 6 c$ in Sertoli cells (referred to as $P p p 6 c^{c K O}$ ) were created by crossing $P p p 6 c^{F / F}$ mice with $A M H$-Cre mice. The $P p p 6 c^{F / F}$ (referred to as $P p p 6 c^{W T}$ ) male mice were defined as control. Both these mouse lines have C57BL/6 J genomic background. Genotyping PCR for Ppp6c gene was experimented using the following primers: forward: GCAGAGGATGGGGTCACATAG, and reverse: ATCTCTGAACCAATTCTGGAG. The PCR conditions were as follows: $94^{\circ} \mathrm{C}$ for $5 \mathrm{~min} ; 35$ rounds of $94^{\circ} \mathrm{C}$ for $30 \mathrm{sec}, 56^{\circ} \mathrm{C}$ for $30 \mathrm{sec}$, and $72{ }^{\circ} \mathrm{C}$ for $30 \mathrm{sec}$; and $72^{\circ} \mathrm{C}$ for $5 \mathrm{~min}$. Genotyping PCR for $A M H-$ Cre was experimented using the following primers: forward: TCCAATTACT GACCGTACACCAA, and reverse: CCTGTACCTGGCAATTTCGGCTA. The PCR conditions were as follows: $94^{\circ} \mathrm{C}$ for $5 \mathrm{~min} ; 35$ rounds of $94^{\circ} \mathrm{C}$ for $30 \mathrm{sec}$, $62^{\circ} \mathrm{C}$ for $30 \mathrm{sec}$, and $72{ }^{\circ} \mathrm{C}$ for $30 \mathrm{sec}$; and $72^{\circ} \mathrm{C}$ for $5 \mathrm{~min}$.

\section{Antibodies}

PPP6C antibody (rabbit, A300-844A; Bethyl Laboratories, Inc.); SYCP3 antibody (rabbit, NB300-231; Novus Biologicals); a-tubulin antibody (rabbit,
2144; Cell Signaling Technology, Inc.); $\beta$-actin antibody (mouse, 3700; Cell Signaling Technology, Inc.); Phospho- $\beta$-Catenin (Ser552) (D8E11) antibody (rabbit, 5651; Cell Signaling Technology, Inc.); SYCP3 antibody (mouse, sc74569; Santa Cruz); $\mathrm{YH} 2 \mathrm{AX}$ antibody (rabbit, 9718; Cell Signaling Technology, Inc.); MVH antibody (mouse, ab27591; abcam); SYCP1 antibody (rabbit, ab15090; abcam); SOX9 antibody (rabbit, AB5535, Sigma-Aldrich); PLZF antibody (goat, AF2944, R\&D Systems); $\beta$-catenin antibody (rabbit, 51067-1-AP, Proteintech); ZO2 antibody (rabbit, 18900-1AP, Proteintech); TEX14 antibody (rabbit, 18351-1-AP, Proteintech); Vimentin antibody (rabbit, 10366-1-AP, Proteintech); HA-Tag mab (mouse, AE008; ABclonal); c-Myc antibody (mouse, m4439; sigma); greenfluorescent Alexa Fluor ${ }^{\circledast} 488$ conjugate of lectin PNA (L21409, Thermo). Horseradish peroxidase-conjugated secondary antibodies were purchased from Zhongshan Golden Bridge Biotechnology Co, LTD (Beijing). Alexa Fluor 488-conjugated antibody and Alexa Fluor 594-conjugated antibody were purchased from Life Technologies.

\section{Breeding assay}

Males (8-9 weeks) of different groups were individually performed for the experiment. Each male mouse was caged with two wild-type ICR strain females, then vaginal plugs were checked every morning. The number of pups in each cage was counted within a week of birth. Each male underwent at least six cycles of the above breeding assay.

\section{Immunoblotting}

To prepare protein extracts, Sertoli cells isolated from testes were put into cold RIPA buffer supplemented with protease and phosphatase inhibitor cocktail (Roche Diagnostics). Then, the Sertoli cell lysates were incubated on ice for $20 \mathrm{~min}$ and centrifuged at $4^{\circ} \mathrm{C}, 12000 \mathrm{rpm}$ for $15 \mathrm{~min}$. 
The supernatant was transferred to a new tube and equal volume $2 x$ loading buffer was added. After being boiled at $95^{\circ} \mathrm{C}$ for $10 \mathrm{~min}$, the lysates were used for immunoblotting.

\section{Tissue collection and histological examination}

In this part, at least three adult mice for each group were experimented in each group. After euthanasia, testes and caudal epididymides were dissected immediately. The samples were fixed in $4 \%$ paraformaldehyde or Bouin's fixative overnight, dehydrated in an ethanol series, and embedded in paraffin wax. Then, the samples were cut into $5 \mu \mathrm{m}$ sections with a microtome. After $42{ }^{\circ} \mathrm{C}$ overnight drying, the sections were deparaffinized in xylene, hydrated by a graded alcohol series, and stained with hematoxylin and eosin for histological analysis. Images were collected with a Nikon inverted microscope with a charge-coupled device (CCD) (Nikon, Eclipse Ti-S, Tokyo, Japan).

\section{Immunofluorescence}

Testes were fixed in $4 \%$ paraformaldehyde $(\mathrm{pH} 7.4)$ overnight at $4{ }^{\circ} \mathrm{C}$, dehydrated, and embedded in paraffin. The samples were cut into $5 \mu \mathrm{m}$ sections with a microtome. Then, the sections were deparaffinized, immersed in sodium citrate buffer $(\mathrm{pH} \mathrm{6.0)}$ and heated for $15 \mathrm{~min}$ in a microwave for antigen retrieval. After blocking with $5 \% \mathrm{BSA}$, samples were incubated with primary antibodies at $4{ }^{\circ} \mathrm{C}$ overnight. The samples were incubated with an appropriate FITC-conjugated secondary antibody. Finally, nuclei were stained with DAPI. Images were captured by using confocal microscope (Zeiss 880).

For the combination of lectin histochemistry and $\mathrm{IHC}$, sampls were first treated with IHC for cell markers observation and then with lectin $(1: 400)$ $30 \mathrm{~min}$ at room temperature to visualize the acrosomes.

\section{TUNEL assay}

TUNEL assay was carried out in accordance with the DeadEnd ${ }^{T M}$ Fluorometric TUNEL System (Promega BioSciences, Madison, WI, USA). Images were captured using a laser scanning confocal microscope (Zeiss 880 META).

\section{Flow cytometry analysis}

The cauda epididymides were dissected from 2-month adult mice. Cells were extruded from the cauda epididymides and washed with PBS three times at $37 \mathrm{C}$. Then, the cells were collected by centrifugation at $600 \times g$ for $5 \mathrm{~min}$. Next the cells were suspended and stained with Hoechst 33342 for $30 \mathrm{~min}$, and were then analyzed using a FACSCalibur flow cytometer (BD).

\section{Isolation of mouse primary sertoli cells}

Primary Sertoli cells were isolated using a method previously described by van der Wee with minor modification [47]. Briefly, the testes of 5-7 dpp mice were removed and decapsulated under a dissection microscope. The seminiferous tubules were torn into small pieces and washed with PBS three times. The tubules were incubated in PBS containing $2 \mathrm{mg} / \mathrm{ml}$ collagenase (Sigma, C5138, St. Louis, MO, USA) and $1 \mathrm{mg} / \mathrm{ml}$ DNase I (Solarbio, D8071) at $37^{\circ} \mathrm{C}$ for $30 \mathrm{~min}$ with gentle shaking. Then, the cells were collected by centrifugation at $100 \times g$ for $1 \mathrm{~min}$ at $4{ }^{\circ} \mathrm{C}$ and washed twice with PBS. Next, the cells further digested with $2 \mathrm{mg} / \mathrm{ml}$ collagenase I, $1 \mathrm{mg} / \mathrm{ml}$ DNase I, and $1 \mathrm{mg} / \mathrm{ml}$ hyaluronidase (Sigma, H3506) for 20-30 min at $37^{\circ} \mathrm{C}$ with gentle shaking. The tubules were allowed to settle and were then washed twice with PBS before being digested with $2 \mathrm{mg} / \mathrm{ml}$ collagenase I, $1 \mathrm{mg} / \mathrm{ml}$ DNase I, $2 \mathrm{mg} / \mathrm{ml}$ hyaluronidase, and $1 \mathrm{mg} / \mathrm{ml}$ trypsin(Sigma, T8003) for $20 \mathrm{~min}$ at $37^{\circ} \mathrm{C}$. This final digestion step resulted in a cell suspension containing primarily Sertoli cells and type A spermatogonia. The dispersed cells were then washed twice with DMEM/F12 and placed into culture dishes in DMEM/F12 containing $10 \%$ fetal calf serum and incubated at $37{ }^{\circ} \mathrm{C}$ and $5 \% \mathrm{CO}_{2}$. After a 1-day culture, the cells were treated with a hypotonic solution ( $20 \mathrm{mM}$ Tris, pH7.4) for $2 \mathrm{~min}$ to remove germ cells. After 3 days culture, total proteins were extracted as described above for Western blot.

\section{Phosphoproteome sample preparation and phosphopeptide enrichment}

For phosphoproteome preparation, primary Sertoli cells from ten mice in each group were pooled to obtain about $1 \mathrm{mg}$ of protein lysate. Primary Sertoli cells were isolated using a method above described by van der Wee with minor modification [47]. The phosphoproteome experiment was supported by Jingjie PTM BioLabs. The Sertoli cells were lysed with lysis buffer supplemented with Phosphatase Inhibitor Cocktail and Protease Inhibitor Cocktail and precipitated with $4 \times$ volumes of $-20^{\circ} \mathrm{C}$ acetone for $4 \mathrm{~h}$. Then precipitated protein was collected by centrifuging for $5 \mathrm{~min}$ at $4500 \mathrm{~g}\left(4^{\circ} \mathrm{C}\right)$, pellets washed twice with $-20^{\circ} \mathrm{C} 80 \%$ acetone, and air-dried upside down for $\sim 10 \mathrm{~min}$ at RT or until no residual acetone odor remained. Pellets were resuspended in $8 \mathrm{M}$ carbamide. Then protein concentration was determined with a BCA assay kit according to the manufacturer's instructions. Then samples were digested with trypsin. For phosphopeptide enrichment, digested peptide mixtures were incubated with an IMAC microsphere suspension. The IMAC microspheres with enriched phosphopeptides were collected by centrifugation, and the supernatant was removed. Then the IMAC microspheres were washed. Finally, the supernatant was collected and lyophilized for the LC-MS/MS.

\section{LC-MS/MS analysis}

The peptides were dissolved in $0.1 \%$ formic acid, directly loaded onto a home-made reversed-phase analytical column. Peptides were separated and were subjected to Capillary source followed by the tims-TOF Pro (Bruker Daltonics) mass spectrometry.

\section{Database search}

The resulting MS/MS data were processed using MaxQuant search engine (v.1.6.6.0). Tandem mass spectra were searched against the Mus musculus swissprot database (17045 entries) concatenated with reverse decoy database. Trypsin/P was specified as a cleavage enzyme allowing up to two missing cleavages. False discovery rate (FDR) was adjusted to $<1 \%$.

\section{Phosphoproteome bioinformatics data analysis}

We performed bioinformatic analysis by using the Perseus software environment. Statistical analysis of phosphoproteome was performed on logarithmized intensities for those values that were found to be quantified in any experimental condition. Gene Ontology (GO) annotation proteome was derived from the UniProt-GOA database (http://www.ebi.ac.uk/GOA/). Kyoto Encyclopedia of Genes and Genomes (KEGG) database was used to annotate protein pathway.

\section{Plasmid construction and In vitro phosphatase assay}

Mouse Ppp6c gene (NM_024209.3) was cloned into pCS2+ vector and mouse Ctnnb1 gene (NM_001165902) was cloned into pCMV vector. Mutagenesis was used to gain plasmids encoding PPP6C with amino acids Asp84 replaced by Asn according to the manufacturer's instruction (KOD -Plus- Mutagenesis Kit, SMK-101). 293 T cells were transfected with PPP6CMyc, PPP6C-D84N-Myc, or CTNNB1-HA plasmid. Then, we performed immunoprecipitations by using anti-Myc or anti-HA antibody, after $36 \mathrm{~h}$ of transfection. After several washes with PBS, immunoprecipitated PPP6CMyc or PPP6C-D84N-Myc and CTNNB1-HA were incubated in phosphatase assay buffer at $25^{\circ} \mathrm{C}$ for $1 \mathrm{~h}$ for the phosphatase assay. The samples were diluted with $2 x$ loading buffer. After being boiled at $95^{\circ} \mathrm{C}$ for $10 \mathrm{~min}$, the samples were used for immunoblotting.

\section{Statistical analysis}

All assays were performed at least three times. Paired two-tailed Student's $\mathrm{t}$-test was used for statistical analysis. Data were presented as mean $\pm \mathrm{SEM}$ and $P<0.05\left(^{*}\right), 0.01\left(^{* *}\right)$ or $0.001\left(^{* *}\right)$ was considered statistically significant.

\section{DATA AVAILABILITY}

All data, including its supplementary information files, supporting the findings of this study are included in this published article. The mass spectrometry proteomics data have been deposited to the ProteomeXchange Consortium (http://proteomecentral. proteomexchange.org) via the PRIDE partner repository with the dataset identifier PXD028051.

\section{REFERENCES}

1. Oatley JM, Brinster RL. Regulation of spermatogonial stem cell self-renewal in mammals. Annu Rev Cell Dev Biol. 2008;24:263-86.

2. Page SL, Hawley RS. Chromosome choreography: the meiotic ballet. Sci. 2003;301:785-9.

3. Nagaoka SI, Hassold TJ, Hunt PA. Human aneuploidy: mechanisms and new insights into an age-old problem. Nat Rev Genet. 2012;13:493-504. 
4. Jégou B. The Sertoli-germ cell communication network in mammals. Int Rev Cytol. 1993;147:25-96.

5. Siu MK, Cheng CY. Dynamic cross-talk between cells and the extracellular matrix in the testis. Bioessays. 2004;26:978-92.

6. Russell L. Movement of spermatocytes from the basal to the adluminal compartment of the rat testis. Am J Anat. 1977;148:313-28.

7. Cheng CY, Mruk DD. The blood-testis barrier and its implications for male contraception. Pharm Rev. 2012;64:16-64.

8. Hartsock A, Nelson WJ. Adherens and tight junctions: structure, function and connections to the actin cytoskeleton. Biochim Biophys Acta. 2008;1778:660-9.

9. Inselman A, Handel MA. Mitogen-activated protein kinase dynamics during the meiotic G2/MI transition of mouse spermatocytes. Biol Reprod. 2004;71:570-8.

10. Bielinski VA, Mumby MC. Functional analysis of the PP2A subfamily of protein phosphatases in regulating Drosophila S6 kinase. Exp Cell Res. 2007;313:3117-26.

11. Cohen PT, Philp A, Vazquez-Martin C. Protein phosphatase 4-from obscurity to vital functions. FEBS Lett. 2005:579:3278-86.

12. Lei W-L, Qian W-P, Sun Q-Y. Critical Functions of PP2A-Like Protein Phosphotases in Regulating Meiotic Progression. Front Cell Dev Biol. 2021;9:638559.

13. Couzens AL, Knight JD, Kean MJ, Teo G, Weiss A, Dunham WH, et al. Protein interaction network of the mammalian Hippo pathway reveals mechanisms of kinase-phosphatase interactions. Sci Signal. 2013;6:rs15.

14. Ye J, Shi H, Shen Y, Peng C, Liu Y, Li C, et al. PP6 controls T cell development and homeostasis by negatively regulating distal TCR signaling. J Immunol. 2015; 194:1654-64.

15. Chen J, Peterson RT, Schreiber SL. Alpha 4 associates with protein phosphatases 2A, 4, and 6. Biochem Biophys Res Commun. 1998;247:827-32.

16. Yan S, Xu Z, Lou F, Zhang L, Ke F, Bai J, et al. NF-kappaB-induced microRNA-31 promotes epidermal hyperplasia by repressing protein phosphatase 6 in psoriasis. Nat Commun. 2015;6:7652.

17. Sutton A, Immanuel D, Arndt KT. The SIT4 protein phosphatase functions in late G1 for progression into S phase. Mol Cell Biol. 1991;11:2133-48.

18. Chen F, Archambault V, Kar A, Lio P, D'Avino PP, Sinka R, et al. Multiple protein phosphatases are required for mitosis in Drosophila. Curr Biol. 2007;17:293-303.

19. Zeng K, Bastos RN, Barr FA, Gruneberg U. Protein phosphatase 6 regulates mitotic spindle formation by controlling the T-loop phosphorylation state of Aurora A bound to its activator TPX2. J Cell Biol. 2010;191:1315-32.

20. Douglas $P$, Zhong J, Ye R, Moorhead GB, Xu X, Lees-Miller SP. Protein phosphatase 6 interacts with the DNA-dependent protein kinase catalytic subunit and dephosphorylates gamma-H2AX. Mol Cell Biol. 2010;30:1368-81.

21. Lei WL, Han F, Hu MW, Liang QX, Meng TG, Zhou Q, et al. Protein phosphatase 6 is a key factor regulating spermatogenesis. Cell Death Differ. 2020;27:1952-64.

22. Hu MW, Wang ZB, Teng Y, Jiang ZZ, Ma XS, Hou N, et al. Loss of protein phosphatase 6 in oocytes causes failure of meiosis II exit and impaired female fertility. J Cell Sci. 2015;128:3769-80.

23. Lecureuil C, Fontaine I, Crepieux P, Guillou F. Sertoli and granulosa cell-specific Cre recombinase activity in transgenic mice. Genesis. 2002;33:114-8.

24. Nakata H, Wakayama T, Takai Y, Iseki S. Quantitative analysis of the cellular composition in seminiferous tubules in normal and genetically modified infertile mice. J Histochem Cytochem. 2015;63:99-113.

25. Ahmed EA, de Rooij DG. Staging of mouse seminiferous tubule cross-sections. Methods Mol Biol. 2009;558:263-77.

26. Kulak NA, Pichler G, Paron I, Nagaraj N, Mann M. Minimal, encapsulated proteomic-sample processing applied to copy-number estimation in eukaryotic cells. Nat Methods. 2014;11:319-24.

27. Greenbaum MP, Yan W, Wu MH, Lin YN, Agno JE, Sharma M, et al. TEX14 is essential for intercellular bridges and fertility in male mice. Proc Natl Acad Sci. 2006;103:4982-7.

28. Weber JE, Russell LD, Wong V, Peterson RN. Three-dimensional reconstruction of a rat stage V Sertoli cell: II. Morphometry of Sertoli-Sertoli and Sertoli-germ-cell relationships. Am J Anat. 1983;167:163-79.

29. Fang D, Hawke D, Zheng Y, Xia Y, Meisenhelder J, Nika H, et al. Phosphorylation of $\beta$-Catenin by AKT Promotes $\beta$-Catenin Transcriptional Activity. J Biol Chem. 2007;282:11221-9.

30. Hammond D, Zeng K, Espert A, Bastos RN, Baron RD, Gruneberg U, et al. Melanoma-associated mutations in protein phosphatase 6 cause chromosome instability and DNA damage owing to dysregulated Aurora-A. J Cell Sci. 2013;126:3429-40.

31. Hu MW, Meng TG, Jiang ZZ, Dong MZ, Schatten $H, X u X$, et al. Protein Phosphatase 6 Protects Prophase I-Arrested Oocytes by Safeguarding Genomic Integrity. PLoS Genet. 2016;12:e1006513.

32. Berruti G, Paiardi C. The dynamic of the apical ectoplasmic specialization between spermatids and Sertoli cells: the case of the small GTPase Rap1. Biomed Res Int. 2014;2014:635979.
33. Lie PP, Cheng CY, Mruk DD. The biology of the desmosome-like junction a versatile anchoring junction and signal transducer in the seminiferous epithelium. Int Rev Cell Mol Biol. 2011;286:223-69.

34. O'Donnell L, Nicholls PK, O'Bryan MK, McLachlan RI, Stanton PG. Spermiation: the process of sperm release. Spermatogenesis. 2011;1:14-35.

35. Huttlin EL, Jedrychowski MP, Elias JE, Goswami T, Rad R, Beausoleil SA, et al. A tissue-specific atlas of mouse protein phosphorylation and expression. Cell. 2010;143:1174-89.

36. Mann M, Ong SE, Grønborg M, Steen H, Jensen ON, Pandey A. Analysis of protein phosphorylation using mass spectrometry: deciphering the phosphoproteome. Trends Biotechnol. 2002;20:261-8.

37. Morin PJ. beta-catenin signaling and cancer. Bioessays. 1999;21:1021-30.

38. Peifer $M$, Polakis $P$. Wnt signaling in oncogenesis and embryogenesis-a look outside the nucleus. Sci. 2000;287:1606-9.

39. Aberle $\mathrm{H}$, Schwartz $\mathrm{H}$, Kemler R. Cadherin-catenin complex: protein interactions and their implications for cadherin function. J Cell Biochem. 1996;61:514-23.

40. Kimelman $\mathrm{D}, \mathrm{Xu} \mathrm{W}$. beta-catenin destruction complex: insights and questions from a structural perspective. Oncogene. 2006;25:7482-91.

41. Su Y, Fu C, Ishikawa $S$, Stella A, Kojima $M$, Shitoh $K$, et al. APC is essential for targeting phosphorylated beta-catenin to the SCFbeta-TrCP ubiquitin ligase. Mol Cell. 2008;32:652-61.

42. MacDonald BT, Tamai $\mathrm{K}, \mathrm{He} \mathrm{X}$. Wnt/ $\beta$-catenin signaling components, mechanisms, and diseases. Dev Cell. 2009;17:9-26.

43. Lustig B, Jerchow B, Sachs M, Weiler S, Pietsch T, Karsten U, et al. Negative feedback loop of Wnt signaling through upregulation of conductin/axin2 in colorectal and liver tumors. Mol Cell Biol. 2002;22:1184-93.

44. Chang H, Gao F, Guillou F, Taketo MM, Huff V, Behringer RR. Wt1 negatively regulates -catenin signaling during testis development. Development. 2008; 135:1875-85.

45. Boyer A, Hermo L, Paquet M, Robaire B, Boerboom D. Seminiferous tubule degeneration and infertility in mice with sustained activation of WNT/ CTNNB1 signaling in sertoli cells1. Biol Reprod. 2008;79:475-85.

46. Tanwar PS, Kaneko-Tarui T, Zhang L, Rani P, Taketo MM, Teixeira J. Constitutive WNT/Beta-catenin signaling in murine sertoli cells disrupts their differentiation and ability to support spermatogenesis1. Biol Reprod. 2010;82:422-32.

47. van der Wee KS, Johnson EW, Dirami G, Dym TM, Hofmann MC. Immunomagnetic isolation and long-term culture of mouse type A spermatogonia. J Androl. 2001;22:696-704.

\section{ACKNOWLEDGEMENTS}

We appreciate and acknowledge Shiwen Li and Xili Zhu for their technical assistance. We thank all members of the Sun lab for their help and discussion. We thank Drs Xingzhi Xu and Xiao Yang for providing the Ppp $6 c^{F / F}$ mice.

\section{AUTHOR CONTRIBUTIONS}

W.L. and Q.S. conceived and designed the experiments; W.L., Y.L., T.M., Y.N., S.S., and C.Z. and L.S. performed the biological experiments; Y.G. and Z.W. analyzed the data; W.L. wrote the paper; W.Q. and Q.S. revised the manuscript. All authors read and approved the final manuscript.

\section{FUNDING}

This study was supported by National Natural Science Foundation of China (31530049), Guangdong Basic and Applied Basic Research Foundation (2020A1515011414), the Project for Research Team of Female Reproductive Health and Fertility Preservation (SZSM201612065), the Project for Medical Discipline Advancement of Health and Family Planning commission of Shenzhen Municipality (SZXJ2018075) and the Shenzhen High-level Hospital Construction Fund.

\section{ETHICS STATEMENT}

The study does not involve human participants, human data, or human tissue. All animal operations were approved by the Animal Research Committee principles of the Institute of Zoology, Chinese Academy of Sciences.

\section{COMPETING INTERESTS}

The authors declare no competing interests. 


\section{ADDITIONAL INFORMATION}

Supplementary information The online version contains supplementary material available at https://doi.org/10.1038/s41419-021-04172-y.

Correspondence and requests for materials should be addressed to Zhen-Bo Wang, Wei-Ping Qian or Qing-Yuan Sun.

Reprints and permission information is available at http://www.nature.com/ reprints

Publisher's note Springer Nature remains neutral with regard to jurisdictional claims in published maps and institutional affiliations.
Open Access This article is licensed under a Creative Commons Attribution 4.0 International License, which permits use, sharing, adaptation, distribution and reproduction in any medium or format, as long as you give appropriate credit to the original author(s) and the source, provide a link to the Creative Commons license, and indicate if changes were made. The images or other third party material in this article are included in the article's Creative Commons license, unless indicated otherwise in a credit line to the material. If material is not included in the article's Creative Commons license and your intended use is not permitted by statutory regulation or exceeds the permitted use, you will need to obtain permission directly from the copyright holder. To view a copy of this license, visit http://creativecommons. org/licenses/by/4.0/.

(c) The Author(s) 2021 